\title{
Diagnóstico socio-educativo y comunitario desde la unidad educativa Leonor de Fernández. Municipio Mara, estado Zulia-Venezuela
}

\author{
Social educational and community diagnosis from the educational unit Leonor de Fernandez. \\ Mara municipality, Zulia state-Venezuela \\ Diagnóstico sócio-educativo e comunitário desde a unidade educativa Leonor de Fernández. \\ Município Mara, estado Zulia-Venezuela
}

DOI: http://dx.doi.org/10.21803\%2Fpenamer.11.21.533

Eric Enrique Ancianis Castro https://orcid.org/0000-0002-6889-9767

Aura Alicia Sayago Giménez https://orcid.org/0000-0003-3672-752X

Andreina Beatriz Hernández https://orcid.org/0000-0003-3672-752X

\section{¿Cómo citar este artículo?}

Ancianis, E., Sayago, A. \& Hernandez, A. (2018) Diagnóstico socio-educativo y comunitario desde la unidad educativa Leonor de Fernández. Municipio Mara, estado Zulia - Venezuela. Pensamiento Americano, 11(21), 181-204

DOI:http://dx.doi.org/10.21803\%2Fpenamer.11.21.533

\section{Resumen}

Este estudio presenta un diagnóstico socio - educativo y comunitario desde la Unidad Educativa Leonor de Fernández, municipio Mara, estado Zulia-Venezuela 2014-2015, el mismo se deriva de un proyecto investigativo, adscrito al CONDES-LUZ. Para determinar las características del área de estudio, se aplicó el diagnóstico de comunidad como ejes que permite abordar, bajo la categoría tiempo y espacio, situaciones actuales, buscando en el pasado elementos que definen la estructura espacial; luego retornar al presente y analizar e interpretar, mediante réplicas cartográficas nociones y conceptos geohistóricos de la relación hombre - Medio. Metodológicamente, la investigación es exploratoria, descriptiva y de Campo, apoyada en cuantificaciones; tomando una muestra de 67 estudiantes de educación primaria y 15 informantes claves. En el proceso de recolección de datos, se aplicó la técnica: observación directa, los métodos: geográfico, de conjuntos y cartográfico. Como instrumentos se utilizaron: guías geográficas, encuestasy entrevistas. La importancia del estudio radica en proponer éstos resultados, como elemento integrador del proceso de aprendizaje en centros educativos de educación primaria. Cabe destacar que el conocimiento de la información por parte del docente y estudiante, favorecen la relación escuela - comunidad y la formulación de alternativas que mejoren la calidad de vida en el contexto geográfico.

PALABRAS CLAVE: Diagnostico de la Comunidad, Geografía Local, Contenidos Geográficos y Enseñanza - Aprendizaje.

\begin{abstract}
This study presents a socio - educational and community diagnosis from the Leonor de Fernández Educational Unit, Mara municipality, Zulia Venezuela state 2014-2015, it is derived from a research project, attached to CONDES - LUZ. In order to determine the characteristics of the study area, the community diagnosis was applied as axes that allow addressing, under the category of time and space, current situations, looking in the past for elements that define the spatial structure; then return to the present and analyze and interpret, through cartographic replicas, notions and geohistorical concepts of the man - Middle relationship. Methodologically, the research is exploratory, descriptive and of Field, supported in quantifications; taking a sample of 67 elementary school students and 15 key informants. In the data collection process, the technique was applied: direct observation, the methods: geographical, set and cartographic. The following instruments were used: geographical guides, surveys and interviews. The importance of the study lies in proposing these results, as an integrating element of the learning process in educational centers of primary education. It should be noted that the knowledge of information by the teacher and student, favor the relationship school - community and the formulation of alternatives that improve the quality of life in the geographical context.
\end{abstract}

KEYWORDS: Diagnosis of the Community, Local Geography, Geographical Contents and Teaching - Learning. 


\section{Resumo}

Este estudo apresenta um diagnóstico sócio - educativo e comunitário desde a Unidade Educativa Leonor de Fernández, município Mara, estado Zulia-Venezuela 2014-2015, o mesmo se origina de um projeto de pesquisa adscrito al CONDES-LUZ. Para determinar as características da área de estudo se aplicou um diagnóstico de comunidade como eixos que permitem abordar, sob a categoria tempo e espaço, situações atuais, buscando no passado elementos que definem a estrutura espacial; logo retornar ao presente e analisar e interpretar, diante reproduções cartográficas, noções e conceitos geo-históricos da relação homem -Meio. Metodologicamente, a pesquisa é exploratória, descritiva, e de campo, apoiada nas quantificações, tomando uma amostra de 67 estudantes de educação primária e 15 informantes-chave. No processo de coleta de dados se aplicou a técnica: observação direta, os métodos: geográfico, de conjuntos e cartográficos. Como instrumentos se utilizaram: guias geográficas, questionários e entrevistas. A importância do estudo radica em propor esses resultados como elemento integrador do processo de aprendizagem em centros educativos de educação primária. Cabe destacar que o conhecimento da informação por parte do docente e estudante favorece a relação escola-comunidade, e a formulação de alternativas que melhorem a qualidade de vida no contexto geográfico.

PALAVRAS CHAVE: Diagnóstico da Comunidade, Geografia Local, Conteúdos Geográficos e Ensino-Aprendizagem.

\section{Perfil}

MSc., en Geografía mención Docencia, doctorante en Educación

UNERMB. Docente Universitario LUZ-Col y en Educación Media General, Investigador en Instituciones Educativas. Adscrito al Centro de Estudios Geográficos LUZ. Auxiliar y Asistente de Investigación en proyectos registrados en CONDES-LUZ. PEII Investigador A2.

E-mail: eric.ancianis@hotmail.com

\section{Perfil}

MSc. Geografía mención Docencia. Investigadora en Centros Educativos. Adscrita al Centro de Estudios Geográficos LUZ. Responsable de proyectos registrados en CONDES-LUZ. PPI Nivel II 2008. PEII Investigador A2.

E-mail: aurasayago42@gmail.com

\section{Perfil}

MSc., en Geografía mención Docencia. Docente en Educación Media General y Primaria. Investigadora en Instituciones Educativas. Asistente de Investigación en proyectos registrados en CONDES-LUZ. E-mail: andreinahernandezp@hotmail.com

Eric Enrique Ancianis Castro Lcolo. Educación mención Geografía.

Aura Alicia Sayago Giménez Lcda. Educación mención Ciencias Sociales.

Andreina Beatriz Hernández Lcdo. Educación mención Geografía. 


\section{Introducción}

E presente artículo muestra un diagnóstico socio-educativo y comunitario, como resultado de un proyecto investigativo denominado Propuesta Pedagógica: Experiencia metodológica fundamental para la construcción del saber geográfico, a través del enfoque geohistórico, administrado por el Consejo de Desarrollo Científico y Humanístico de la Universidad del Zulia (CONDES-LUZ). El mismo, revela parte del contexto espacial, como material de apoyo teórico - metodológico para orientar los procesos investigativos y de enseñanza - aprendizaje de la geografía local, especialmente, en los centros educativos, localizados en el área objeto de este estudio. Es importante señalar que la enseñanza se ha venido desempeñando de manera "...transmisible, lo que origina una acentuada indiferencia, neutralidad y apatía, que trae como consecuencia un desfase de la tarea de educar con el momento histórico e impide confrontar la espacialidad geográfica" (Santiago, 1997 p. 09).

Conviene destacar que la geografía es una ciencia que abarca varias disciplinas, ya que ella estudia un conjunto de elementos tanto físicos como humanos en el planeta, lugar en el cual habita la sociedad, con el fin de utilizar a éste para múltiples funciones que le sea individual y colectivamente favorable. Por lo tanto, la geografía demanda fortalecer los contenidos de aprendizaje, donde los mismos dejen de ser un acto mecánico y rutinario sin concordancia con la realidad inmediata, donde los estudiantes experimentan actividades monótonas, desfasadas y por consiguiente alejadas de su entorno local, sin el logro de un aprendizaje adecuado, siendo éste aquel saber pertinente que perdura como un conocimiento propio de lo dado.

Asimismo, dicha ciencia debe constituir uno de los pilares de primer orden, para propiciar y consolidar la formación de ciudadanos con valores éticos, morales, cívicos y culturales, que permitan la participación responsable en la transformación de la sociedad, ya que ésta se enmarcan en los "...ideales presentes en la Constitución de la República Bolivariana de Venezuela, para desarrollar un ser social y político que (...) se muestre autónomo, participativo; valorándose así mismo, corresponsable de su comportamiento, desde su realidad, para transformarla" (Ministerio del Poder Popular para la Educación. Currículo: Subsistema de Educación Primaria, 2007 p. 22).

La geográfica dispone de enfoques para el estudio de espacios estructurados por los grupos humanos en sociedad, permitiendo construir nociones y conceptos que expliquen las condiciones socioeconómicas, culturales y educativas a diferentes escalas. En atención a ello, este estudio toma en cuenta el contexto escolar y local como objeto principal dentro de la teoría geográfica, la cual busca entender los aspectos del entorno, tanto históricos como geográficos, “... por eso debe estudiar la evolución histórica, la estructura social, las relaciones sociedad - naturaleza, la organización y estructura productiva a la escala de las agrupaciones urbanas y rurales que forman núcleos de agrupamiento humano" (Carvajal, 2001 p. 9).

Es por esto que, es pertinente la aplicación de técnicas, métodos, herramientas e instrumentos que proporcionan los enfoques geográficos, para abordar la colectividad donde residen la población estudiantil, que bien puede ser un barrio, un conjunto residencial, un caserío, una aldea u otras formas de ocupación humana espacial, lo que implica una primera aproximación al estudio de la ciencia, es decir, aprender a partir de preguntas lógicas. Si se formulan interrogantes interesantes se podrá llegar a resultados novedosos; si se es capaz de discernir nuevos aspectos llamativos 
que han marcado la vida de la escuela y comunidad se podría avanzar hacia la comprensión de otras formas de organización social. En el fondo la lógica de estudiar la geografía local, reside en que primero se debe conocer lo cercano, es decir, ese espacio cotidiano que se recorre diariamente y que puede representar una experiencia para cada uno de los seres humanos organizados en sociedad.

Al hacer uso de esas múltiples especificaciones o procedimientos en el contexto geográfico, se puede emprender la búsqueda de las fuerzas internas y externas que moldean la vida de los asentamientos humanos, claro como toda investigación científica, lo primero es tener una situación a resolver, para llegar a resultados socialmente útiles. También, se debe saber qué es lo que se busca, para al final del estudio prever hasta dónde llegar, ya que en ciencia él que no sabe lo que busca no sabe lo que encuentra.

El primer factor de organización para la investigación tiene que ser, naturalmente, la propia situación de investigación, con sus objetivos, teorías y procedimientos metodológicos que lo sustentan. No todos los estudios de carácter científico tienen por finalidad poner a prueba una hipótesis. Muchas investigaciones como estas tienen como propósito explorar, describir o explicar fenómenos, grupos, instituciones, comunidades y muchos otros elementos, pero resulta evidente que cuanto más conocemos el objeto de estudio mucho más tentados se está de resolverlos por la vía de descubrimiento o hipótesis.

Para abordar la realidad de la investigación se plantea como objetivo general: determinar las condiciones socio-educativas y comunitarias del sector La Nueva Lucha, desde la U.E. Leonor de Fernández, municipio Mara del estado Zulia. Dicho objetivo es operacionalizado mediante las subsecuentes acciones específicas a saber: 1. Explorar las condiciones socio-económicos, educativos, culturales y locales de la población en el área de estudio, desde el diagnóstico de la comunidad como herramienta del enfoque geohistórico; 2. Ejecutar el método de los conjuntos como procedimiento estadístico adecuado para la organización, procesamiento, análisis e interpretación de la información; 3. Diseñar representaciones cartográficas que expliquen la dinámica socioeconómica y comunitaria de la población escolar en el sector La Nueva Lucha municipio Mara, estado Zulia; y 4. Proponer el diagnóstico como contenidos de enseñanza en centros educativos vinculados al espacio geográficos seleccionado. Cabe aclarar que los resultados de éste último objetivo, formaran parte de un nuevo proceso investigativo de carácter pedagógicos a desarrollarse en la unidad educativa, donde fue elaborado en presente diagnóstico, con la finalidad de valorar la importancia que tiene el diagnóstica de la comunidad, para iniciar los procesos de aprendizaje de la geografía local, en espacios del municipio Mara.

Los planteamientos expresados se apoyan en un cuerpo sistemático de principios teóricos - metodológicos, enmarcados en la ciencia geográfica. Por ello, se presentan conocimientos descriptivos relacionados entre sí, sustentados en el enfoque geohistórico, el cual, permite abordar al espacio como producto social, donde la organización y estructura depende del conjunto de relaciones entre la sociedad y la naturaleza que se tejen sobre el espacio y el hombre plasma en un momento determinado (Herrera, Lugo y Pereira, 1991). De allí que, la investigación, propicia el acercamiento al estudio, explicación y comprensión del espacio social, pues, ofrece la oportunidad de reconocer e interpretar la realidad desde varias ópticas, a fin de plantear alternativas de solución a los acontecimientos comunitarios.

En tal sentido, para indagar y describir parte 
de la situación socio-educativa y comunitaria del área en estudio, se acudió a la herramienta: el diagnóstico de la comunidad como eje que permite analizar, bajo las categorías de tiempo y espacio, situaciones actuales, es decir, busca en el pasado elementos definidores de la estructura espacial, para luego retornar al presente y ofrecer un análisis del comportamiento de los hombres en sociedad. Donde, la noción geohistórica “...se desprende de la propia concepción geográfica que entiende al espacio como un producto concreto o síntesis de la acción de los grupos humanos sobre el medio ambiente para su necesaria conservación y reproducción sujetos a condiciones históricas determinadas" (Tovar, 1996 p. 52).

Ahora bien, el diagnóstico de la comunidad, simboliza un procedimiento para contextualizar el ambiente escolar y local, ya que facilita la búsqueda, clasificación, procesamiento, análisis e interpretación de la información vinculada al ámbito seleccionado. Al respecto, Sayago y León (2000) plantean que éste “... ayuda al individuo a conocer su realidad en su caracterización social, económica y cultural, lo que le permite analizarla y plantear alternativas posibles de solución a los problemas de la comunidad" (p. 251). Dicha herramienta es útil para la investigación e intervención directa del espacio que se desea abordar, puesto que conlleva al conocimiento de las fortalezas, oportunidades, debilidades y amenazas en el área social, aprovechando de esta manera la información suministrada para la solución de situaciones.

Para Ceballos (2008), el diagnóstico impulsa a conocer la acción educativa como un proceso de formación, considerando la escuela como elemento integrante del espacio producido por la sociedad y medio capaz de generar transformaciones; conllevando así a determinar condiciones reales de recursos humanos, materiales y niveles biopsicosociales. A partir del análisis de estos elementos se establecen proposiciones que permiten la integración de los procesos de enseñanza y aprendizaje, los cuales, tiene como fin desarrollar al máximo las potencialidades, motivaciones y aspiraciones para la búsqueda de alternativas de solución a las situaciones en el ámbito escolar y local. En vista de dichos supuestos esta herramienta se ha convertido en un referente pedagógico para abordar el espacio geográfico, ya que supera la construcción curricular y se inserta en la realidad social - comunitaria que compromete una dualidad de intención: la formación integral, la capacitación para la vida y el espacio geográfico, siendo éste no sólo un soporte físico, por el contrario sirve de asiento al comportamiento social y pedagógico (Sayago y León, 2000).

Definitivamente, en el espacio local es donde se perciben con mayor claridad las interrelaciones de la sociedad con su medio, parte del entorno inmediato se modifica al igual que el nivel de información al pasar por cada uno de los estadios. Estos mecanismos son necesarios para los efectos de su plena comprensión y explicación, pues facilita la visión de las conexiones y permite la generalización. Al incorporarlos al saber social, asimilarán los límites y las posibilidades que le ofrece su localidad para actuar. Se resalta, así la acción social en su relación con la naturaleza, los conflictos y contradicciones materializada en la transformación y humanización del medio que explican su forma, dinámica y propio proceso de producción. Desde esta perspectiva, el espacio objeto de estudio, resulta de la construcción de los grupos humanos que organizados, determinan su forma, función y significación social; la escuela y comunidad constituyen el espacio donde se desarrolla la vida, ya que allí sentimos, conocemos, movemos y comportamos toda nuestra actividad humana. 
A manera de colofón, la geografía local conlleva al estudio de la realidad específica de un determinado espacio geográfico, para indagar su historia, geografía y relación entre el hombre - sociedad - naturaleza. Siendo el espacio geográfico “...un fenómeno complejo en el que se expresa la materialidad de las relaciones sociales en un determinado momento histórico, en unas determinadas condiciones sociales y en una ubicación geográfica" (Romero, Ortega, Arango, Norgué, Albet, Méndez, Nel-Lo, Muñoz, Farinós y Naredo. 2004 p. 34). La cual, tiene que ver con las escalas espaciales en el que se desenvuelven dichas relaciones.

\section{Procedimiento metodológico}

Para avanzar en el desarrollo del estudio se llevó a cabo un procedimiento metodológico, con base exploratoria, descriptiva y de Campo, con el apoyo de algunas cuantificaciones y operacionalizaciones de la información que permitieron una mejor comprensión del hecho estudiado. Exploratoria, ya que la misma "...se efectúa sobre un tema u objeto poco conocido o estudiado, por lo que sus resultados constituyen una visión aproximada de dicho objeto" (Arias, 2005 p. 46). En este contexto, se busca indagar datos significativos para la sistematización del estudio, alcanzando de esta manera una visión aproximada del tema permitiendo una descripción clara y sistemática. Descriptiva, porque consiste en ordenar los hechos donde se subraya una red característica de acciones de carácter empírico y observacionales sobre una situación.

Posteriormente, de campo, pues “...recoge la información directa de la realidad" (Pérez, 2005 p. 20). No es más que el contacto inmediato con el objeto, con el fin de recolectar datos, favoreciendo el acercamiento o conexión con la realidad, destacándose los hechos e información relevante para el de- sarrollo de la investigación; obteniendo de esta manera lo pertinente del espacio donde se desenvuelven los acontecimientos geográficos. Así como también, cuantitativa, permitiendo realizar descripción de los datos organizados y resumidos en tablas de frecuencia (absoluta y relativa), facilitando su interpretación. Esto con ayuda del método de los conjuntos como procedimiento estadístico de la matemática aplicada, que conlleva al ordenamiento de datos, y se constituye en un instrumento de gran flexibilidad, facilitando la organización de conjuntos y subconjuntos, para sintetizar e interpretar los datos obtenidos.

Para lograr parte de la exploración se tomó en cuento una muestra de 67 estudiantes, cursantes de la Segunda Etapa de Educación Primaria (4to, 5to y 6 to grado), de la U.E. Leonor de Fernández, durante el período escolar 2014-2015. Así como también, el lugar de residencia de dicha población escolarizada y 15 informantes claves, habitantes en el sector La Nueva Lucha, Km 26 vía El Moján, parroquia Ricaurte, municipio Mara del estado Zulia.

Ahora bien, partiendo de la base de que no existe sólo una estrategia o procedimiento general válido en la investigación; este estudio se apoyó en técnicas, métodos e instrumentos que conllevaron a la organización y procesamiento de la información. Entre ellos se destaca: Primero, la técnica de la observación directa, siendo ésta "...la capacidad para descomponer o identificar las partes de un todo y reunificarlas para reconstruir este todo" (Cerda, 2005 p. 238). Visto de esta forma se consideró esa facultad para identificar y conocer el conjunto de cualidades, partes de los objetos y fenómenos de la realidad que actúan directamente sobre los sentidos, con el fin de obtener información aproximada del espacio local intervenido. 
Segundo, los métodos: geográfico, de los conjuntos y cartográfico, como basamentos teórico-prácticos que radican en emprender el estudio del contexto local y escolar. Ellos facilitaron el procesamiento de los datos recolectados mediante el diagnóstico, logrando descubrir y definir parte del dinamismo presente en la comunidad, estableciendo conexión con el contexto comunitario. Por cuanto, el geográfico, permitió abordar la realidad socio-espacial; producto de las relaciones sociedad-naturaleza; hecho que explica y analiza la organización de un espacio y su estructura presente, cuya concreción no es más que la síntesis como sustento metodológico (González, 1998, citado por Ancianis, 2007 p. 52).

El de los conjuntos, conllevó al "...tratamiento de datos estadísticos, puesto que trabaja el concepto de grupo o conjunto. Brinda flexibilidad cuando permite la organización de conjuntos y subconjunto en una totalidad y el estudio de espacios geográficos a diferentes escalas" (Sayago y León, 2000 p. 252). Éste, accede a la organización sistemática de los elementos o categorías de análisis estudiado en un espacio geográfico determinado. Y el cartográfico, siendo la última acción permite representar el sistema de relaciones: económicas, políticas, sociales, culturales y educativas, estructurales dominantes en el espacio abordado y en un período histórico dados.

Es por ello que, el cartográfico no es más que la representación teórico - metodológica de la realidad objeto de estudio ya que hace objetiva la síntesis geográfica, sirviendo como instrumento de trabajo y es utilizado para la explicación u orientación del proceso de investigación emprendido en las ciencias sociales, específicamente, la geografía. En definitiva, es una forma de expresión de la realidad del espacio, que va- liéndose de la observación directa, registro y procesos de reflexión, permiten la captación de lugares concretos que conducen a la conceptualización de elementos actuales en la localidad. La réplica de la realidad se organiza por medio de una representación cartográfica, que recoge las contradicciones y leyes que caracterizan la dinámica del espacio o realidad objetiva y por ende el comportamiento de la sociedad. (Ancianis, 2007).

Y tercero, las guías de información geográficas aplicadas a la comunidad (viaje, contexto espacial, educativa, informantes claves, subsistema construido y productivo), encuesta socioeconómica, dirigida a los estudiantes y la entrevista cara a caca, seleccionada para la población residente en el área objeto de estudio. Los referidos instrumentos permitieron la búsqueda de información de los elementos y características esenciales del contexto espacial. Una vez recopilados los datos, fue necesario procesarlos matemáticamente, apoyándose en el método de los conjuntos y la estadística descriptiva, llegando así a la cuantificación y tratamiento accediendo al análisis e interpretación de los resultados, convirtiéndose éstos en información de gran valor y significado para la comunidad educativa en general.

Cabe destacar, que el procedimiento metodológico planteado, se organizó en cuatro fases, operacionalizadas en momentos, los cuales configuran y resumen la base sobre la cual se desarrolla la investigación (Figura 1). Según Sevillano (2005), este proceso se puede enmarcar dentro de estos aspectos: a). Recolección y reducción de los datos, b). Disposición y transformación de los mismos, y c). Obtención de resultados, conclusiones y recomendaciones.

\section{Diagnóstico educativo y comunitario}

En esta sección se expone la organización de 


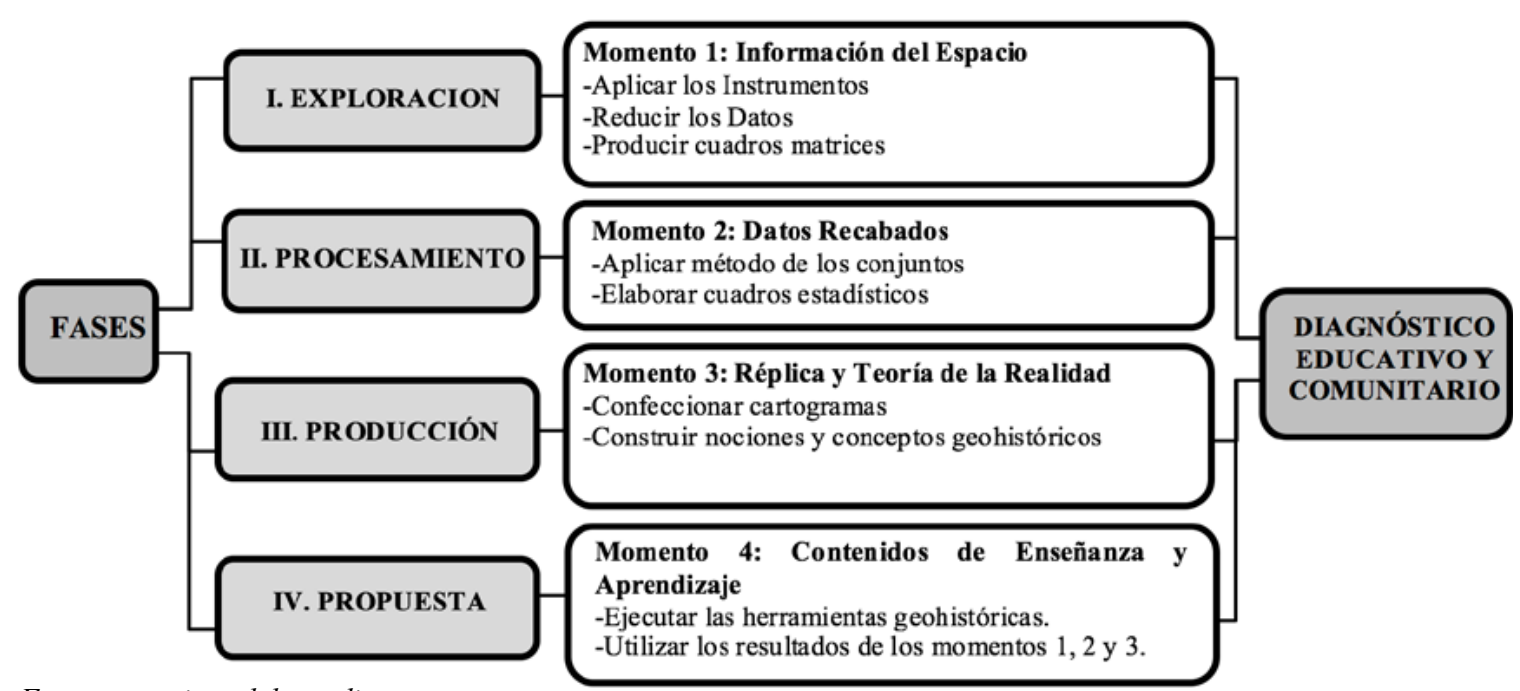

Figura 1. Fases operativas del estudio

Fuente: Diario del Investigador

los resultados obtenidos, producto de la ejecución de la fase uno, dos y tres formulada de este estudio, lo cual responde a la sucesión de los objetivos específicos uno, dos y tres. La operacionalización de dicha fase (I), fue por medio de sus tres momentos, que respondieron a la exploración realizada en el contexto comunitario (sector La Nueva Lucha) y educativo (U.E. Leonor de Fernández), para obtener una visión general de lo que interesa y sirva de eje orientador en los procesos de enseñanza y aprendizaje de la geografía en el área objeto del estudio.

\subsection{Contexto Educativo}

La exploración fue realizada para indagar aspectos socioeconómicos, culturales y educativos de la población cursante en la modalidad de Educación Primaria, a fin de proponer los resultados como contenido de enseñanza y aprendizaje. Para Ceballos (2008), esta exploración impulsa a conocer la acción socioeducativa como un proceso de formación permanente y a considerar la escuela como elemento integrante del espacio producido por la sociedad y medio capaz de generar transformaciones (Santiago, 2016). A continuación, se presentan los resultados analizados e interpretados, tomando en cuenta las guías de información presentadas por la autora antes mencionada, las cuales, establecieron las pautas a seguir:

\subsubsection{Guía de Información Escolar:}

Identificación del Centro Educativo: Se designa como U.E "Leonor de Fernández", ubicada en el sector La Nueva Lucha, Km 26 vía El Moján, parroquia Ricaurte, municipio Mara del estado Zulia (Cartograma 1).

Reseña Histórica: Las raíces históricas del centro educativo ya mencionado, se enmarcan en 1978, cuando miembros de la comunidad les surge la inquietud de crear una "Escuelita", para formar a sus niños, niñas y adolescentes, en su mayoría pertenecientes a la etnia indígena Wayuú. Esta idea fue retomada por la maestra Esperanza Moncada, la cual comenzó a impartir sus conocimientos a un pequeño grupo, éste con el transcurrir del tiempo fue incrementándose. La constante lucha de la maestra, logró un espacio más amplio y asignado en calidad de comodato. Con ayuda de los miembros de la comunidad, construyó una enramada, allí con entusiasmo se comenzó a impartir actividades de aprendizaje el 15 de junio de 1979. La vocación, dedicación y disposición 
de la docente impulsó a seguir buscando un sitio en mejores condiciones para los estudiantes.

Para 1980, el señor Luis González, dueño de varias parcelas en la zona, facilitó un espacio con mayor amplitud, lugar donde se encontraba un árbol de nombre "Curarire" que servía de refugio y recreación a la comunidad. En ese entonces la "Escuelita" se denominó Nueva Lucha, atendiendo al nombre del sector. Posteriormente, la comunidad logró que la escuela pasara a un Núcleo Escolar Rural (N.E.R), registrada bajo en el N ${ }^{\circ 68}$ y dirigida por el maestro Orlando Villalobos. En 1984 se construyó una R1, de bloques y techo de zinc, quedando como directora la maestra Esperanza Moncada, a partir de esta fecha se le asignó el nombre: Escuela Básica Nacional "La Nueva Lucha", auspiciada por la Organización para la Educación, la Ciencia y la Cultura de las Naciones Unidas (UNESCO).

A partir de este momento, la escuela aumento su matrícula, para darle prosecución a la población escolar se creó la primera y segunda etapa de Educación Básica. Luego en 1987 se apertura la sala de preescolar, dirigida por la maestra Mary de Ramos; asimismo, ingresaron al plantel los maestros: Neudy González, Ernesto Jiménez, Juana Hernández, entre otros, quienes formaron parte del personal docente. Durante ese mismo año, Esperanza Moncada, por problemas de salud, deja la dirección, asumiendo Sabina Rosa Arias como sub-directora.

El 19 de diciembre de 1995, la Zona Educativa Zulia, emitió la circular N 535, asignándole a la Unidad Educativa el epónimo: Doña Leonor de Fernández, quien se desempeñó como maestra con mucho amor por la educación y vocación de servicio, pues considera a los estudiantes como sus hijos pre- dilectos. Asimismo, la infraestructura creció, gracias al aporte de la Fundación de Edificaciones y Dotaciones Escolares (F.E.D.E) y Obras Públicas del Estado (O.P.E). Desde el 24 de octubre de 1998 el Gobierno Regional inició el Programa de Alimentación Escolar del Zulia (PAEZ), para satisfacer parte de las necesidades de la comunidad estudiantil en el sector La Nueva Luchas y sus áreas de influencia.

En el 2003, Sabina Arias, solicitó su jubilación y en septiembre del mismo año, la Jefatura Escolar del municipio Mara nombró a Luz Marina Fernández como sub-directora. Ella propuso un proyecto conjuntamente con padres, representantes, docentes y estudiantes, sobre las necesidades urgentes en la institución, el cual fue llevado a la Jefatura Escolar para ser revisado, corregido y entregarlo al Alcalde del municipio, Ingeniero Luis Gerardo Caldera, quien delega funciones a Carbones del Zulia, ubicado en el municipio Mara (CARBOZULIA) y FEDE para el desarrollo de dicho proyecto.

En el período escolar 2004 - 2005 los representantes plantearon la necesidad de continuar con la tercera etapa de Educación Básica, en vista de que la escuela poseía una población de bajos recursos económicos y los planteles educativos (liceos) se ubican en otras áreas distantes al sector. Al respecto, las docentes Luz Marina Fernández y Gladis Nava, junto a la comunidad tomaron la iniciativa de crear secciones de primer año (A y B). Seguidamente, se generó la inclusión de segundo, tercero, cuarto y quinto para atender la prosecución escolar de la población. En vista del acelerado crecimiento de la matrícula escolar, en 2008 se inició al mejoramiento y ampliación de la Unidad Educativa, bajo gestiones gubernamentales. Finalizando, este proyecto de infraestructura en febrero de 2011 (Santiago, 2016). 
Característica Generales: Actualmente, la institución ofrece la Educación Primera y Media General; posee una matrícula de 1000 estudiantes aproximadamente, organizada en 25 secciones, funcionan en dos turnos (matutino y vespertino). Está adscrita al Ministerio del Poder Popular para la Educación, es decir, una institución Educativa Bolivariana de carácter oficial/nacional.

Área de Influencia de la Población Estudiantil: El área de influencia de la U. E., se corresponde con el sector La Nueva Lucha (17.9\%), Corazón de Mara (16.4\%), El Mecocal (16.4\%), Simón Bolívar (14.9\%), Las Cruces (8.9\%) y Las Mandocas (8.9\%). Esto explica el traslado de la población escolar, donde el $62.6 \%$ de los

Tabla 1.

Lugar de residencia y medio de transporte estudiantes se movilizan a pie, debido a la cercanía de su residencia al centro educativo. A esto se unen el 20,8\% que utilizan el transporte escolar (Tabla 1 y Representación Cartográfica 1).

Problemas y Alternativas: La población escolarizada, a través de la encuesta socioeconómi$\mathrm{ca}$, expresa que existen una serie de irregularidades que afectan el centro educativo, entre ellos se destacan: instalaciones en condiciones infrahumanas (41.4\%), falta de baños (22.7\%) e insuficiencia de pupitres y pizarras (15.4\%). Estos datos declaran las debilidades que poseen en relación a infraestructura y dotación. Para el mejoramiento los estudiantes argumentan alternativas de solución, como: culminar con la

\begin{tabular}{|c|c|c|c|c|c|c|c|}
\hline Lugar & V.A & V.R (\%) & Cat. & Transporte & V.A & V.R (\%) & Cat. \\
\hline La Nueva lucha & 12 & 17.9 & \multirow{3}{*}{$\begin{array}{l}\text { Rango } \\
\text { Fuerte }\end{array}$} & A Pie & 42 & 62.6 & \multirow{2}{*}{$\begin{array}{c}\text { Rango } \\
\text { Fuerte } \\
>>\end{array}$} \\
\hline Corazón de Mara & 11 & 16.4 & & $\begin{array}{l}\text { Transporte } \\
\text { Escolar }\end{array}$ & 14 & 20.8 & \\
\hline El Mecocal & 11 & 16.4 & & Bicicleta & 5 & 7.4 & \\
\hline Simón Bolívar & 10 & 14.9 & \multirow[t]{3}{*}{$>$} & $\begin{array}{l}\text { Carro } \\
\text { Particular }\end{array}$ & 3 & 4.4 & \multirow{3}{*}{$\begin{array}{c}\text { Rango } \\
\text { Débil } \\
<\end{array}$} \\
\hline Las Cruces & 6 & 8.9 & & Moto & 2 & 2.9 & \\
\hline Las Mandocas & 6 & 8.9 & & Autobús & 1 & 1.4 & \\
\hline Las Quince Letras & 5 & 7.4 & \multirow{5}{*}{$\begin{array}{c}\text { Rango } \\
\text { Débil } \\
<\end{array}$} & Total & 67 & $99.5 \%$ & \\
\hline El Veintisiete & 2 & 2.9 & & & & & \\
\hline Shipia Wayuu & 2 & 2.9 & & & & & \\
\hline San Andrés & 1 & 1.4 & & & & & \\
\hline Monte Claro & 1 & 1.4 & & & & & \\
\hline Total & 67 & $99.3 \%$ & & & & & \\
\hline
\end{tabular}

Aplicación del Método de los Conjuntos: $M=100 / N . M=100 / 11=9.0 ; 100 / 6=16.6$.

Nota: V.A: Valor Absoluto V.R: Valor Relativo (\%) Cat: Categoría. Mayor Que (>), Menor Que (<)

Fuente: Encuesta Socioeconómica. II Etapa de Educación Básica. Elaboración: Equipo de Investigación 2014. 
estructura física de la escuela (52.6\%) y trabajar en conjunto para recaudar fondos y reparar pupitres, enramadas, así como otras áreas de la institución (19.7\%) (Tabla 2).

Situación Socioeconómica: Mediante la encuesta, aplicada a la muestra de estudiantes, con el fin de determinar aspectos generales que los caracterizan; en relación con el género se refleja el femenino (53.7\%). ante el masculino (46.3\%). Esta muestra es oriunda de los municipios Maracaibo (70.1\%) y Mara (San Rafael) (22.3\%); asimismo, sus edades oscilan entre diez y quince años, resaltando el $41.7 \%, 23,0 \%$ y $20.8 \%$ estudiantes de doce, once y trece años respectivamente (Tabla 3).

En cuantoal número de miembros que conforman el núcleo familiar tenemos que el $20.8 \%$ se ajustan a cinco y seis personas por familia, el $16.4 \%$ equivale a cuatro y $10.4 \%$ a siete integrantes. Seguidamente, se observa en primer lugar el número de adultos, donde un 55.2\% se corresponde a dos y $14.9 \%$ a cuatro personas mayores por familia. $Y$ en segundo lugar, el número de niños conformado por tres (37.3\%), dos (26.8\%) y cuatro (14.9\%) infantes. Esto revela que la mayor parte de ellas tienen a su cuidado de dos a cuatro niños (Tabla 4).

Con respecto a cuántos trabajan en el núcleo familiar, se puede apreciar que el $62.6 \%$ trabajan dos personas y $19.4 \%$ solo una desempeña algún oficio, representando estas dos categorías el carácter relevante. Paralelo a esto se tiene cuántos estudian, donde el 33.8\% revela tres, $27.6 \%$ dos, $13.8 \%$ una y $13.8 \%$ cuatro personas por familia. Por otra parte, el $71.6 \%$ de los estudiantes declaran que conviven con ambos padres y el 23.8\% solo con mamá (Tabla 5).

En cuanto al lugar de nacimiento de los padres y madres, un porcentaje de ellos y ellas son nativos de los municipios Maracaibo (62.6\%, $47.7 \%)$ y Mara $(10.4 \%, 20.8 \%)$ respectivamente,

Tabla 2.

Problemas y alternativas de solución del centro educativo

\begin{tabular}{|c|c|c|c|c|c|c|c|}
\hline Problemas & V.A & V.R (\%) & Cat. & $\begin{array}{c}\text { Alternativas } \\
\end{array}$ & V.A & V. $\mathbf{R}(\%)$ & Cat. \\
\hline $\begin{array}{l}\text { Instalaciones en malas } \\
\text { condiciones. }\end{array}$ & 56 & 41.1 & \multirow{3}{*}{$\begin{array}{l}\text { Rango } \\
\text { Fuerte } \\
\quad>\end{array}$} & Terminan la construcción escolar. & 40 & 52.6 & \multirow{2}{*}{$\begin{array}{l}\text { Rango } \\
\text { Fuerte } \\
\quad>\end{array}$} \\
\hline Falta de baños. & 31 & 22.7 & & $\begin{array}{l}\text { Trabajar en conjunto para recaudar } \\
\text { fondos, reparar pupitres, } \\
\text { enramadas y baños. }\end{array}$ & 15 & 19.7 & \\
\hline $\begin{array}{l}\text { Insuficiencia de } \\
\text { pupitres y pizarras. }\end{array}$ & 21 & 15.4 & & $\begin{array}{l}\text { Que el consejo comunal preste su } \\
\text { ayuda para mejorar las enramadas } \\
\text { mientras terminan la escuela. }\end{array}$ & 10 & 13.1 & \multirow{5}{*}{$\begin{array}{l}\text { Rango } \\
\text { Débil } \\
<\end{array}$} \\
\hline $\begin{array}{l}\text { Ausencia de filtros de } \\
\text { agua. }\end{array}$ & 11 & 8.0 & \multirow{7}{*}{$\begin{array}{l}\text { Rango } \\
\text { Débil } \\
<\end{array}$} & Que haya vigilancia y seguridad. & 7 & 9.2 & \\
\hline Inseguridad. & 8 & 5.8 & & $\begin{array}{l}\text { Que padres y representantes } \\
\text { colaboren con el botiquín de } \\
\text { primeros auxilios. }\end{array}$ & 2 & 2.6 & \\
\hline $\begin{array}{lll}\begin{array}{l}\text { Deficiencia en } \\
\text { electricidad. }\end{array} & & \\
\end{array}$ & 4 & 2.9 & & Llegar antes del horario establecido. & 1 & 1.3 & \\
\hline $\begin{array}{l}\text { Deterioro de cancha } \\
\text { deportiva. }\end{array}$ & 3 & 2.2 & & Realizar actividades recreativas. & 1 & 1.3 & \\
\hline $\begin{array}{l}\text { Escasez de 1primeros } \\
\text { auxilios. }\end{array}$ & 1 & 0.7 & & Total & 76 & $99.8 \%$ & \\
\hline $\begin{array}{lr}\text { Impuntualidad } & \text { de } \\
\text { docentes } & y \\
\text { estudiantes. } & \\
\end{array}$ & 1 & 0.7 & & & & & \\
\hline Total & 136 & $99.7 \%$ & & & & & \\
\hline
\end{tabular}


Tabla 3 .

Edad y lugar de nacimiento

\begin{tabular}{|c|c|c|c|c|c|c|c|}
\hline Edad & V.A & V.R (\%) & Cat. & Lugar & V.A & V.R (\%) & Cat. \\
\hline 12 & 28 & 41.7 & \multirow{3}{*}{$\begin{array}{c}\text { Rango } \\
\text { Fuerte } \\
>\end{array}$} & Maracaibo & 47 & 70.1 & \multirow{2}{*}{$\begin{array}{c}\text { Rango } \\
\text { Fuerte } \\
>\end{array}$} \\
\hline 11 & 16 & 23.8 & & Mara (San Rafael) & 15 & 22.3 & \\
\hline 13 & 14 & 20.8 & & La Nueva Lucha & 2 & 2.9 & \multirow{4}{*}{$\begin{array}{c}\text { Rango } \\
\text { Débil } \\
<\end{array}$} \\
\hline 10 & 6 & 8.9 & \multirow{3}{*}{$\begin{array}{c}\text { Rango } \\
\text { Débil } \\
<\end{array}$} & Santa Cruz & 1 & 1.4 & \\
\hline 14 & 4 & 2.9 & & La Sierrita & 1 & 1.4 & \\
\hline 15 & 1 & 1.5 & & Cuatro Bocas & 1 & 1.4 & \\
\hline total & 67 & $99.5 \%$ & & total & 67 & $99.5 \%$ & \\
\hline
\end{tabular}

Aplicación del Método de los Conjuntos: $M=100 / N . M=100 / 6=16.6$.

Nota: V.A: Valor Absoluto V.R: Valor Relativo (\%) Cat: Categoría. Mayor Que (>), Menor Que (<)

Fuente: Encuesta Socioeconómica. II Etapa de Educación Básica. Elaboración: Equipo de Investigación 2014.

Tabla 4 .

Número de personas, adultos y niños del núcleo familiar

\begin{tabular}{|c|c|c|c|c|c|c|c|c|c|c|c|}
\hline Personas & V.A & V.R (\%) & Cat. & Adultos & V.A & V.R (\%) & Cat. & Niños & V.A & V.R (\%) & Cat. \\
\hline 5 & 14 & 20.8 & \multirow{4}{*}{$\begin{array}{c}\text { Rango } \\
\text { Fuerte } \\
>\end{array}$} & 2 & 37 & 55.2 & \multirow{2}{*}{$\begin{array}{c}\text { Rango } \\
\text { Fuerte } \\
>\end{array}$} & 3 & 23 & 34.3 & \multirow{3}{*}{$\begin{array}{c}\text { Rango } \\
\text { Fuerte } \\
>\end{array}$} \\
\hline 6 & 14 & 20.8 & & 4 & 10 & 14.9 & & 2 & 18 & 26.8 & \\
\hline 4 & 11 & 16.4 & & 3 & 7 & 10.4 & \multirow{5}{*}{$\begin{array}{c}\text { Rango } \\
\text { Débil } \\
<\end{array}$} & 4 & 10 & 14.9 & \\
\hline 7 & 7 & 10.4 & & 1 & 5 & 7.4 & & 5 & 7 & 10.4 & \multirow{4}{*}{$\begin{array}{c}\text { Rango } \\
\text { Débil } \\
<\end{array}$} \\
\hline 3 & 6 & 8.9 & \multirow{4}{*}{$\begin{array}{c}\text { Rango } \\
\text { Débil } \\
<\end{array}$} & 8 & 5 & 7.4 & & 1 & 6 & 8.9 & \\
\hline 8 & 5 & 7.4 & & 6 & 2 & 2.9 & & 7 & 2 & 2.9 & \\
\hline 9 & 3 & 4.4 & & 7 & 1 & 1.4 & & 6 & 1 & 1.4 & \\
\hline 10 & 3 & 4.4 & & Total & 67 & $99.6 \%$ & & Total & 67 & $99.6 \%$ & \\
\hline
\end{tabular}

Tabla 5.

Cuántos trabajan, estudian y con quien convives

\begin{tabular}{|c|c|c|c|c|c|c|c|c|c|c|c|}
\hline Trabajan & V.A & $\begin{array}{l}\text { V.R } \\
\text { (\%) }\end{array}$ & Cat. & Estudian & V.A & $\begin{array}{l}\text { V.R } \\
\text { (\%) }\end{array}$ & Cat. & Convives & V.A & $\begin{array}{l}\text { V.R } \\
\text { (\%) }\end{array}$ & Cat. \\
\hline 2 & 42 & 62.6 & \multirow[t]{2}{*}{$\begin{array}{c}\text { Rango } \\
\text { Fuerte } \\
>\end{array}$} & 3 & 12 & 33.8 & \multirow{4}{*}{$\begin{array}{c}\text { Rango } \\
\text { Fuerte } \\
>\end{array}$} & Padres & 48 & 71.6 & $\begin{array}{c}\text { Rango } \\
\text { Fuerte } \\
>\end{array}$ \\
\hline 1 & 13 & 19.4 & & 2 & 18 & 27.6 & & Mamá & 16 & 23.8 & Rango \\
\hline 3 & 6 & 8.9 & \multirow{4}{*}{$\begin{array}{c}\text { Rango } \\
\text { Débil } \\
<\end{array}$} & 1 & 9 & 13.8 & & Abuela & 2 & 2.9 & Débil \\
\hline 4 & 4 & 5.9 & & 4 & 9 & 13.8 & & Papá & 1 & 1.4 & $<$ \\
\hline 5 & 1 & 1.4 & & 5 & 3 & 4.6 & \multirow{4}{*}{$\begin{array}{c}\text { Rango } \\
\text { Débil } \\
<\end{array}$} & Total & 67 & $99.7 \%$ & \\
\hline 6 & 1 & 1.4 & & 6 & 2 & 3.0 & & & & & \\
\hline Total & 67 & $99.6 \%$ & & 7 & 2 & 3.0 & & & & & \\
\hline & & & & Total & 65 & $99.6 \%$ & & & & & \\
\hline
\end{tabular}

Aplicación del Método de los Conjuntos: $M=100 / N . M=100 / 6=16.6 ; 100 / 7=14.2 ; 100 / 4=25$

Nota: V.A: Valor Absoluto V.R: Valor Relativo (\%) Cat: Categoría. Mayor Que (>), Menor Que (<)

Fuente: Encuesta Socioeconómica. II Etapa de Educación Básica. Elaboración: Equipo de Investigación 2014. 
lo que podría enriquecer el crecimiento poblacional de marabinos y marences en el estado Zulia. El resto es de otras zonas del país y de Colombia. Las edades oscilan entre 28 y 56 años, ocupando altos porcentajes los padres con edades de $36-45$ (58.2\%) y las madres entre 36 - 45 (47.7\%) y 28 - 35 años (40.2\%). También, se destaca que un $58.5 \%$ de ellos trabaja, a diferencia de ellas donde el 52.2\% no ocupan un empleo (Tabla 6).

Con referencia al grado de instrucción, el 43.2\% de los padres y $38.8 \%$ de las madres, no culminaron la Educación Básica, ni revelaron su nivel académico (26.8\%), solo culminaron hasta el diversificado un grupo de once madres equivalente al $16.4 \%$ logrando ser bachilleres. Esto confirma los resultados de la profesión u oficio y por consiguiente los ingresos de los padres y madres, donde estos se desenvuelven en actividades relacionadas con la dinámica urbana, es decir, ocupaciones independientes y dependientes.

Entre las profesiones se tiene en el caso de los padres: comerciantes (38.8\%), obreros (35.8\%) y choferes (11.9\%); percibiendo salarios entre mil seiscientos y dos mil quinientos bolívares fuertes semanales. Las madres en un $86.5 \%$ se dedican a desarrollar actividades acordes a su nivel de formación, como: ama de casa (68.6\%) y comerciantes (17,9\%), labores que reflejan su preparación académica que las limita a dedicarse en otras ocupaciones con mayor nivel de ingreso. En relación al grado de motivación que poseen los padres y madres para educarse, el $98.5 \%$ de ellos y $92.5 \%$ de ellas manifiestan desinterés, indicando que actualmente no estudian, solo el $1.4 \%$ y $7,4 \%$ respectivamente, tienen la inquietud de superarse para alcanzar un nivel de vida mejor a su grupo familiar (Tabla 7).

El tipo de vivienda de la población se indica como: casa (85.0\%), rancho (10.4\%), pieza (2.9\%) y quinta (1.4\%), cuya tenencia es propia (94.0\%), pagándola (2.9\%) y al cuido (2.9\%). El uso de la misma corresponde al residencial (98.5\%) solo un $1.4 \%$ es residencial-comercial; finalmente los hogares muestran ser dignos, acogedores y de utilidad familiar. Entre los ambientes que éstas poseen se tiene que más del 90\% cuentan con: dormitorios encontrándose en orden decreciente de tres (41.7\%) a dos (38.8\%) habitaciones; un comedor (97.0\%), sala $(98.5 \%)$, cocina $(100 \%)$ y baño $(85.0 \%)$ (Tabla 8).

Tabla 6 .

Lugar de nacimiento y edad: padres y madres

\begin{tabular}{|c|c|c|c|c|c|c|c|c|c|c|c|c|c|c|c|}
\hline $\begin{array}{l}\text { Lugar: } \\
\text { Padre }\end{array}$ & V.A & $\begin{array}{l}\text { V.R } \\
\text { (\%) }\end{array}$ & Cat. & Edad & V.A & $\begin{array}{l}\text { V.R } \\
(\%)\end{array}$ & Cat. & $\begin{array}{l}\text { Lugar: } \\
\text { Madre }\end{array}$ & V.A & V.R (\%) & Cat. & Edad & V.A & V.R (\%) & Cat. \\
\hline Maracaibo & 42 & 62.6 & \multirow[t]{2}{*}{$\begin{array}{l}\text { Rango } \\
\text { Fuerte } \\
>\end{array}$} & $36-45$ & 39 & 58.2 & $\begin{array}{l}\text { Rango } \\
\text { Fuerte } \\
>\end{array}$ & Maracaibo & 32 & 4.7 .7 & \multirow[t]{2}{*}{$\begin{array}{l}\text { Rango } \\
\text { Fuerte } \\
>\end{array}$} & $36-45$ & 32 & 47.7 & $\begin{array}{l}\text { Rango } \\
\text { Fuerte } \\
>\end{array}$ \\
\hline San Rafael & 7 & 10.4 & & $46-55$ & 15 & 22.3 & \multirow{3}{*}{$\begin{array}{l}\text { Rango } \\
\text { Débil } \\
<\end{array}$} & San Rafael & 14 & 20.8 & & $28-35$ & 27 & 40.2 & \\
\hline Colombia & 4 & 5.9 & \multirow{8}{*}{$\begin{array}{l}\text { Rango } \\
\text { Débil } \\
<\end{array}$} & $28-35$ & 10 & 14.9 & & Tamare & 4 & 5.9 & \multirow{3}{*}{$\begin{array}{c}\text { Rango } \\
\text { Débil } \\
<\end{array}$} & $46-55$ & 6 & 8.9 & \\
\hline Paraguaipoa & 3 & 4.4 & & 56-más & 3 & 4.4 & & Colombia & 3 & 4.4 & & 56-más & 2 & 2.9 & $\begin{array}{l}\text { Rango } \\
\text { Débil } \\
<\end{array}$ \\
\hline La Guajira & 3 & 4.4 & & Total & 67 & 99.8 & & Campo Mara & 2 & 2.9 & & Total & 67 & $99.7 \%$ & \\
\hline Carrasquero & 2 & 2.9 & & & & & & La Guajira & 2 & 2.9 & & & & & \\
\hline Santa Cruz & 2 & 2.9 & & & & & & Santa Cruz & 2 & 2.9 & & & & & \\
\hline Mene Grande & 2 & 2.9 & & & & & & Paraguaipoa & 2 & 2.9 & & & & & \\
\hline Sinamaica & 1 & 1.4 & & & & & & Guárico & 1 & 1.4 & & & & & \\
\hline Mérida & 1 & 1.4 & & & & & & Quince Letras & 1 & 1.4 & & & & & \\
\hline \multirow[t]{2}{*}{ Total } & 67 & $99.2 \%$ & & & & & & Machiques & 1 & 1.4 & & & & & \\
\hline & & & & & & & & Santa Fe & 1 & 1.4 & & & & & \\
\hline \multirow{3}{*}{\multicolumn{8}{|c|}{$\begin{array}{l}\text { Aplicación del Método de los Conjuntos: M=100/N.M=100/10=10; 100/4=25;100/14=7.1. } \\
\text { Nota: V.: Valor Absoluto V.R: Valor Relativo (\%) Cat: Categoria. Mayor Que ( }(>) \text {, Menor Que (<) } \\
\text { Fuente: Encuesta Socioeconómica. II Etapa de Educación Básica. Elaboración: Equipo de Investigación } 2014 \text {. }\end{array}$}} & Carrasquero & 1 & 1.4 & & & & & \\
\hline & & & & & & & & Las Cruces & 1 & 1.4 & & & & & \\
\hline & & & & & & & & Total & 67 & $98.7 \%$ & & & & & \\
\hline
\end{tabular}


Tabla 7.

Grado de instrucción, profesión e ingreso: padres y madres

\begin{tabular}{|c|c|c|c|c|c|c|c|c|c|c|c|}
\hline $\begin{array}{l}\text { Grado: } \\
\text { Padre }\end{array}$ & V.A & $\begin{array}{l}\text { V.R } \\
(\%)\end{array}$ & Cat. & $\begin{array}{c}\text { Profesión: } \\
\text { Padre }\end{array}$ & V.A & $\begin{array}{l}\text { V.R } \\
\text { (\%) }\end{array}$ & Cat. & $\begin{array}{c}\text { Ingreso: } \\
\text { Padre }\end{array}$ & V.A & $\begin{array}{l}\text { V.R } \\
\text { (\%) }\end{array}$ & Cat. \\
\hline $\begin{array}{l}\text { Básica } \\
\text { incompleta }\end{array}$ & 29 & 43.2 & \multirow{2}{*}{$\begin{array}{c}\text { Rango } \\
\text { Fuerte } \\
>\end{array}$} & Comerciante & 26 & 38.8 & \multirow{2}{*}{$\begin{array}{c}\text { Rango } \\
\text { Fuerte } \\
>\end{array}$} & $\begin{array}{l}800- \\
\text { menos }\end{array}$ & 36 & 53.7 & \multirow{2}{*}{$\begin{array}{c}\text { Rango } \\
\text { Fuerte } \\
>\end{array}$} \\
\hline $\begin{array}{l}\text { No } \\
\text { contestaron }\end{array}$ & 18 & 26.8 & & Obrero & 24 & 35.8 & & $800-1600$ & 17 & 25.3 & \\
\hline Bachiller & 10 & 14.9 & \multirow{4}{*}{$\begin{array}{c}\text { Rango } \\
\text { Débil } \\
<\end{array}$} & Chofer & 8 & 11.9 & \multirow{8}{*}{$\begin{array}{c}\text { Rango } \\
\text { Débil } \\
<\end{array}$} & 1600-más & 14 & 20.8 & $\begin{array}{c}\text { Rango } \\
\text { Débil } \\
<\end{array}$ \\
\hline $\begin{array}{l}\text { Básica } \\
\text { completa }\end{array}$ & 5 & 7.4 & & Enfermero & 2 & 2.9 & & Total & 67 & $99.8 \%$ & \\
\hline Superior TSU & 4 & 5.9 & & Docente & 2 & 2.9 & & $\begin{array}{l}\text { Ingreso: } \\
\text { Madre }\end{array}$ & V.A & $\begin{array}{l}\text { V.R } \\
\text { (\%) }\end{array}$ & Cat \\
\hline Analfabeta & 1 & 1.4 & & Electricista & 1 & 1.4 & & $\begin{array}{l}800- \\
\text { menos }\end{array}$ & 50 & 74.6 & $\begin{array}{l}\text { Rango } \\
\text { Fuerte }\end{array}$ \\
\hline Total & 67 & 99.6 & & Militar & 1 & 1.4 & & $800-1600$ & 15 & 22.3 & $>$ \\
\hline $\begin{array}{l}\text { Grado: } \\
\text { Madre }\end{array}$ & V.A & $\begin{array}{l}\text { V.R } \\
\text { (\%) }\end{array}$ & Cat. & Agricultor & 1 & 1.4 & & 1600-más & 2 & 2.9 & $\begin{array}{c}\text { Rango } \\
\text { Débil } \\
<\end{array}$ \\
\hline $\begin{array}{l}\text { Básica } \\
\text { incompleta }\end{array}$ & 26 & 38.8 & \multirow{2}{*}{$\begin{array}{c}\text { Rango } \\
\text { Fuerte } \\
>\end{array}$} & Operador Vial & 1 & 1.4 & & Total & 67 & $99.8 \%$ & \\
\hline $\begin{array}{l}\text { No } \\
\text { contestaron }\end{array}$ & 16 & 23.8 & & $\begin{array}{l}\text { Técnico en } \\
\text { refrigeración }\end{array}$ & 1 & 1.4 & & & & & \\
\hline Bachiller & 11 & 16.4 & \multirow{4}{*}{$\begin{array}{c}\text { Rango } \\
\text { Débil } \\
<\end{array}$} & Total & 67 & $99.3 \%$ & & & & & \\
\hline $\begin{array}{l}\text { Básica } \\
\text { completa }\end{array}$ & 8 & 11.9 & & $\begin{array}{c}\text { Profesión: } \\
\text { Madre }\end{array}$ & V.A & $\begin{array}{l}\text { V.R } \\
\text { (\%) }\end{array}$ & Cat & & & & \\
\hline Superior TSU & 4 & 5.9 & & Ama de casa & 46 & 68.6 & \multirow{2}{*}{$\begin{array}{c}\text { Rango } \\
\text { Fuerte } \\
>\end{array}$} & & & & \\
\hline Analfabeta & 2 & 2.9 & & Comerciante & 12 & 17.9 & & & & & \\
\hline Total & 67 & 99.7 & & Repostera & 3 & 4.4 & & & & & \\
\hline & & & & Cocinera & 3 & 4.4 & & & & & \\
\hline & & & & Costurera & 1 & 1.4 & \multirow{3}{*}{$\begin{array}{c}\text { Rango } \\
\text { Débil } \\
<\end{array}$} & & & & \\
\hline & & & & Enfermera & 1 & 1.4 & & & & & \\
\hline & & & & Docente & 1 & 1.4 & & & & & \\
\hline & & & & Total & 67 & $99.5 \%$ & & & & & \\
\hline
\end{tabular}

Aplicación del Método de los Conjuntos: $M=100 / N . M=100 / 6=16.6 ; 100 / 10=10 ; 100 / 7=14.2 ; 100 / 3=33.3$. Nota: V.A: Valor Absoluto V.R: Valor Relativo (\%) Cat: Categoría. Mayor Que (>), Menor Que (<) Fuente: Encuesta Socioeconómica. II Etapa de Educación Básica. Elaboración: Equipo de Investigación 2014. 
En cuanto a los servicios, la comunidad cuenta mayormente con: electricidad (30.3\%), aseo urbano (21.1\%) y gas (21.1\%), esto demuestra una gran debilidad ya que solo poseen tres servicios básicos. Entre otras condiciones de organización social, se destaca: el Consejo Comunal (82.7\%), Punto de Control (Guardia Nacional) y Cooperativas que no sobrepasan el
$12.6 \%$. Asimismo, áreas recreativas, como canchas deportivas (55.2\%) (Tabla 9).

Con respecto, a la asistencia médica que existe se tiene que la comunidad cuenta con: ambulatorios de Barrio Adentro (75.5\%), Clínica Nutricional (9.1\%), Consultorio Privado (8.1\%) y Casa de Salud (1.0\%). La

Tabla 8 .

Tipo, tenencia, uso y número de ambientes que posee la vivienda

\begin{tabular}{|c|c|c|c|c|c|c|c|c|c|c|c|}
\hline Tipo & V.A & $\begin{array}{l}\text { V.R } \\
\text { (\%) }\end{array}$ & Cat. & Tenencia & V.A & $\begin{array}{l}\text { V.R } \\
\text { (\%) }\end{array}$ & Cat. & $\begin{array}{l}\text { Ambiente: } \\
\text { Dormitorio }\end{array}$ & V.A & $\begin{array}{l}\text { V.R } \\
\text { (\%) }\end{array}$ & Cat. \\
\hline Casa & 57 & 85.0 & $\begin{array}{c}\text { Rango } \\
\text { Fuerte } \\
>\end{array}$ & Propia & 63 & 94.0 & $\begin{array}{c}\text { Rango } \\
\text { Fuerte } \\
>\end{array}$ & 3 & 28 & 41.7 & $\begin{array}{c}\text { Rango } \\
\text { Fuerte } \\
>\end{array}$ \\
\hline Rancho & 7 & 10.4 & \multirow{3}{*}{$\begin{array}{c}\text { Rango } \\
\text { Débil } \\
<\end{array}$} & Pagándola & 2 & 2.9 & \multirow[b]{2}{*}{$\begin{array}{c}\text { Rango } \\
\text { Débil } \\
<\end{array}$} & 2 & 26 & 38.8 & \\
\hline Pieza & 2 & 2.9 & & Al cuido & 2 & 2.9 & & 1 & 8 & 11.9 & \multirow{3}{*}{$\begin{array}{c}\text { Rango } \\
\text { Débil } \\
<\end{array}$} \\
\hline Quinta & 1 & 1.4 & & Total & 67 & 99.8 & & 4 & 4 & 5.9 & \\
\hline \multirow[t]{5}{*}{ Total } & 67 & $99.7 \%$ & & & & & & 5 & 1 & 1.4 & \\
\hline & & & & Uso & V.A & $\begin{array}{l}\text { V.R } \\
\text { (\%) }\end{array}$ & Cat. & Total & 67 & $99.7 \%$ & \\
\hline & & & & Residencial & 66 & $\begin{array}{c}98.5 \\
\%\end{array}$ & $\begin{array}{c}\text { Rango } \\
\text { Fuerte } \\
>\end{array}$ & & & & \\
\hline & & & & $\begin{array}{l}\text { Residencia- } \\
\text { comercial }\end{array}$ & 1 & $1.4 \%$ & $\begin{array}{c}\text { Rango } \\
\text { Débil } \\
<\end{array}$ & & & & \\
\hline & & & & Total & 67 & 99.9 & & & & & \\
\hline
\end{tabular}

Aplicación del Método de los Conjuntos: $M=100 / N . M=100 / 4=24 ; 100 / 3=33.3 ; 100 / 2=50 ; 100 / 5=20$.

Nota: V.A: Valor Absoluto V.R: Valor Relativo (\%) Cat: Categoría. Mayor Que (>), Menor Que (<)

Fuente: Encuesta Socioeconómica. II Etapa de Educación Básica. Elaboración: Equipo de Investigación 2014.

Tabla 9 .

Servicios básicos, comunales y áreas recreativas

\begin{tabular}{|c|c|c|c|c|c|c|c|c|c|c|c|}
\hline Básicos & V.A & $\begin{array}{l}\text { V.R } \\
(\%) \\
\end{array}$ & Cat. & Comunales & V.A & $\begin{array}{l}\text { V.R } \\
(\%) \\
\end{array}$ & Cat. & Áreas & V.A & $\begin{array}{l}\text { V.R } \\
(\%) \\
\end{array}$ & Cat. \\
\hline Electricidad & 40 & 30.3 & \multirow{3}{*}{$\begin{array}{l}\text { Rango } \\
\text { Fuerte } \\
\quad>\end{array}$} & $\begin{array}{l}\text { Consejo } \\
\text { comunal }\end{array}$ & 72 & 82.7 & $\begin{array}{l}\text { Rango } \\
\text { Fuerte } \\
>\end{array}$ & Cancha & 37 & 55.2 & $\begin{array}{l}\text { Rango } \\
\text { Fuerte }\end{array}$ \\
\hline Aseo Urbano & 28 & 21.2 & & $\begin{array}{l}\text { Punto de } \\
\text { control. } \\
\text { (Guardia } \\
\text { nacional) }\end{array}$ & 11 & 12.6 & \multirow{2}{*}{$\begin{array}{l}\text { Rango } \\
\text { Débil } \\
<\end{array}$} & $\begin{array}{l}\text { No } \\
\text { Contestó }\end{array}$ & 29 & 43.2 & $>$ \\
\hline Gas & 28 & 21.2 & & Cooperativas & 4 & 4.5 & & Plaza & 1 & 1.4 & $\begin{array}{l}\text { Rango } \\
\text { Débil } \\
<\end{array}$ \\
\hline No Contestó & 17 & 12.8 & \multirow{4}{*}{$\begin{array}{l}\text { Rango } \\
\text { Débil } \\
<\end{array}$} & Total & 87 & $99.8 \%$ & & Total & 67 & 99.8 & \\
\hline Agua & 16 & 12.1 & & & & & & & & & \\
\hline Transporte & 2 & 1.5 & & \multirow{3}{*}{\multicolumn{8}{|c|}{$\begin{array}{l}\text { Aplicación del Método de los Conjuntos: } M=100 / N . M=100 / 7=14.2 ; 100 / 3=33.3 \text {. } \\
\text { Nota: V.A: Valor Absoluto V.R: Valor Relativo (\%) Cat: Categoría. Mayor Que (>), Menor Que (<) } \\
\text { Fuente: Encuesta Socioeconómica. II Etapa de Educación Básica. Elaboración: Equipo de Investigación } 201\end{array}$}} \\
\hline Acueducto & 1 & 0.7 & & & & & & & & & \\
\hline Total & 132 & $99.8 \%$ & & & & & & & & & \\
\hline
\end{tabular}


población acude en caso de problemas de salud, principalmente, al ambulatorio Barrio Adentro (74.0\%), debido a la proximidad con su residencia y a la atención gratuita (Tabla 10).

Entre los servicios educativos están: escuelas (37.1\%), liceos (26.5\%) y aldea universitaria (16.8\%); y los comerciales, cuenta con: abastos
(25.5\%), comida rápida (13.3\%), farmacia (8.3\%), quincalla (5.9\%), panadería (4.7\%), mercal (4.7\%), taller mecánico (4.7\%) y centro de conexión (4.7\%). Esto demuestra que la población cuenta con espacios para abastecer sus necesidades de salud y alimentación (Tabla 17).

\subsection{Contexto Comunitario}

Al considerar el diagnóstico realizado en la

Tabla 10

Asistencia médica, servicio al que acuden y religión que profesan

\begin{tabular}{|c|c|c|c|c|c|c|c|c|c|c|c|}
\hline Asistencia & V.A & $\begin{array}{l}\text { V.R } \\
\text { (\%) }\end{array}$ & Cat. & Servicio & V.A & $\begin{array}{l}\text { V.R } \\
(\%)\end{array}$ & Cat. & Religión & V.A & $\begin{array}{l}\text { V.R } \\
(\%)\end{array}$ & Cat. \\
\hline Ambulatorio & 74 & 75.5 & $\begin{array}{l}\text { Rango } \\
\text { Fuerte } \\
>\end{array}$ & Ambulatorio & 57 & 74.0 & $\begin{array}{l}\text { Rango } \\
\text { Fuerte } \\
>\end{array}$ & Evangélica & 55 & 69.6 & $\begin{array}{l}\text { Rango } \\
\text { Fuerte } \\
>>\end{array}$ \\
\hline $\begin{array}{l}\text { Clínica } \\
\text { nutricional }\end{array}$ & 9 & 9.1 & \multirow{4}{*}{$\begin{array}{l}\text { Rango } \\
\text { Débil } \\
<\end{array}$} & No contestó & 13 & 16.8 & \multirow{3}{*}{$\begin{array}{l}\text { Rango } \\
\text { Débil } \\
<\end{array}$} & Católica & 16 & 20.2 & \multirow{3}{*}{$\begin{array}{l}\text { Rango } \\
\text { Débil } \\
<\end{array}$} \\
\hline $\begin{array}{l}\text { Consultorio } \\
\text { privado }\end{array}$ & 8 & 8.1 & & $\begin{array}{l}\text { Clínica } \\
\text { nutricional }\end{array}$ & 4 & 5.1 & & $\begin{array}{l}\text { No } \\
\text { contestó }\end{array}$ & 5 & 6.3 & \\
\hline No contestó & 6 & 6.1 & & $\begin{array}{l}\text { Consultorio } \\
\text { privado }\end{array}$ & 3 & 3.8 & & $\begin{array}{l}\text { Testigos de } \\
\text { Jehová }\end{array}$ & 2 & 2.5 & \\
\hline Casa de salud & 1 & 1.0 & & Total & 77 & $99.7 \%$ & & Total & 79 & $98.6 \%$ & \\
\hline Total & 98 & $99.8 \%$ & & \multicolumn{8}{|c|}{$\begin{array}{l}\text { Aplicación del Método de los Conjuntos: } M=100 / N . M=100 / 5=20 ; 100 / 4=25 . \\
\text { Nota: V.A: Valor Absoluto V.R: Valor Relativo (\%) Cat: Categoría. Mayor Que (>), Menor Que (<) } \\
\text { Fuente: Encuesta Socioeconómica. II Etapa de Educación Básica. Elaboración: Equipo de Investigación } 2014 .\end{array}$} \\
\hline
\end{tabular}

Tabla 11 .

Instituciones educativas y actividades comerciales

\begin{tabular}{|c|c|c|c|c|c|c|c|}
\hline Instituciones & V.A & $\begin{array}{l}\text { V.R } \\
(\%)\end{array}$ & Cat. & Comercios & V.A & $\begin{array}{l}\text { V.R } \\
\text { (\%) }\end{array}$ & Cat. \\
\hline Escuela & 42 & 37.1 & \multirow{4}{*}{$\begin{array}{l}\text { Rango } \\
\text { Fuerte } \\
>>\end{array}$} & Abastos & 43 & 25.5 & \multirow[b]{4}{*}{ Rango } \\
\hline Liceo & 30 & 26.5 & & Comida rápida & 19 & 11.3 & \\
\hline No contestó & 20 & 17.6 & & Farmacia & 14 & 8.3 & \\
\hline $\begin{array}{l}\text { Aldea } \\
\text { universitaria }\end{array}$ & 19 & 16.8 & & Quincalla & 10 & 5.9 & \\
\hline Liceo técnico & 1 & 0.8 & \multirow{2}{*}{$\begin{array}{c}\text { Rango } \\
\text { Débil } \\
<\end{array}$} & Panadería & 8 & 4.7 & \multirow[t]{4}{*}{$\begin{array}{c}\text { Fuerte } \\
>\end{array}$} \\
\hline Misión Robinson & 1 & 0.8 & & Mercal & 8 & 4.7 & \\
\hline Total & 113 & $99.6 \%$ & & Taller & 8 & 4.7 & \\
\hline & & & & Centro de conexión & 8 & 4.7 & \\
\hline & & & & Restaurant & 7 & 4.1 & \multirow{14}{*}{$\begin{array}{c}\text { Rango Débil } \\
<\end{array}$} \\
\hline & & & & Frutería & 7 & 4.1 & \\
\hline & & & & Carpintería & 6 & 3.5 & \\
\hline & & & & Ferretería & 5 & 2.9 & \\
\hline & & & & Venta de ropa & 5 & 2.9 & \\
\hline & & & & Supermercado & 4 & 2.3 & \\
\hline & & & & Carnicería & 3 & 1.7 & \\
\hline & & & & Depósito de licor & 3 & 1.7 & \\
\hline & & & & Pedeval & 3 & 1.7 & \\
\hline & & & & Bloquera & 2 & 1.1 & \\
\hline & & & & Emisora radial & 2 & 1.1 & \\
\hline & & & & Floristería & 1 & 0.5 & \\
\hline \multirow{3}{*}{\multicolumn{4}{|c|}{$\begin{array}{l}\text { Do/N.M= } 100 / 6=16.6 ; 100 / 22=4.5 \text {. } \\
\text { 6) Cat: Categoria. Mavor Que (>), Menor Que (<) } \\
\text { Educación Básica. Elaboración: Equipo de Investigación } 2014 .\end{array}$}} & Estación de servicio & 1 & 0.5 & \\
\hline & & & & $\begin{array}{l}\text { Distribuidora de } \\
\text { alimentos }\end{array}$ & 1 & 0.5 & \\
\hline & & & & Total & 168 & 98.3 & \\
\hline
\end{tabular}


comunidad objeto de este estudio, se logran reconocer aspectos fundamentales, referidos a: ubicación geográfica, evolución histórica, subsistema construido (escuelas, centros de salud, rasgos demográficos, culturales y políticos) y actividades económicas/no económicas. Para la recolección y organización se tomaron en cuenta las herramientas teórico - metodológicas del enfoque geohistórico, puesto que éstas conllevan al análisis, interpretación y síntesis de elementos en el espacio geográfico local, relacionados con los aspectos económicos, políticos, sociales, educativos y culturales. Seguidamente, se exponen los resultados comunitarios:

\subsubsection{Guía de Información Espacial:}

Ubicación Geográfica: El sector La Nueva Lucha, se ubica geográficamente en la zona noroccidental del estado Zulia, municipio Mara parroquia Ricaurte, sus límites son al: Norte, parroquias Tamare y San Rafael de El Moján (capital del municipio); Este, Lago de Maracaibo; Sur, municipio Maracaibo (capital del estado) y Oeste, parroquia La Sierrita. Entre sus límites específicos estas las comunidades ecuménicas siguientes: Norte, El Mecocal y Veintisiete; Este, Simón Bolívar y Las Mandocas; Sur, Corazón de Mara y Las Quince Letras, y Oeste, Monte Claro (Cartográfica 2).

Evolución Geohistórica: La ocupación del grupo humano en el sector, se estableció con el objeto de satisfacer sus principales necesidades (alimentación, vestido, vivienda, creencias religiosas); al paso del tiempo se dio cuenta que le era más factible asentarse en un lugar determinado, para aprovechar las bondades que la naturaleza les brindaba. Aquí, se hace énfasis en la génesis de la estructura espacial que presenta "La Nueva Lucha", donde es importante destacar que los lugares van evolucionando continuamente al igual que las relaciones entre ellos, por poseer elementos dinamizadores que los hacen cambiar, ya sea en el ámbito natural (físicos) y construido (sociales); por tal motivo debe existir una congruencia de los elementos para solventar la problemática que se presenta en los diferentes espacios geográficos.

La ocupación y fijación del sector antes mencionado, es principalmente por los grupos aborígenes de la etnia Wayuú y de origen español quienes conformaron asentamientos poblacionales a partir de los años 1940-1960, esta ocupación se originó a finales del gobierno del General Marcos Pérez Jiménez, durante el período geohistórico de la Venezuela del Petróleo. Entre las familias fundadoras están los: Celis Añez, Celis Suárez, González Celis, Villalobos González y Villalobos Villalobos. El Señor Ángel Celis Añez y familia, eran propietario de grandes extensiones de tierra, tenían un hato llamado Las Cruces, donde practicaba la agricultura y producían carbón vegetal. Poseían un abasto denominado La Lucha, aquí actualmente, está el sector Las Mandocas, (antigua carretera principal). Posteriormente, en 1944 construyó otro abasto identificado como La Nueva Lucha, nombre emblemático que expresa el trabaja y lucha día a día. En 1951 fundó la estación de servicio de combustible para vehículos y afines asignada con el nombre La Nueva Lucha.

El primer momento de expansión de la comunidad (1960-1980) ocurre en el período geohistórico de la Venezuela Petrolera, en la cual se evidencia una serie de características de índole social, económico político, cultural, que reflejan el momento de expansión y consolidación del espacio geográfico, con el gobierno del Dr. Raúl Leoni. La comunidad empieza a consolidarse de 
manera lenta pero en ascenso, presentando una población entre 60 a 80 habitantes aproximadamente; éstos ubicados en los sectores Las Cruces y Santa Ana, existiendo allí hatos con grandes extensiones de tierra fértil para el cultivo (estacional) y la ganadería.

En 1978, se funda la primera institución educativa para atender las necesidades estudiantiles de niños y jóvenes del sector, comenzando el año escolar en una vivienda común, la cual, fue evolucionando progresivamente, llevando por nombre Leonor de Fernández. Luego, entre 1981 - 1991, surge el segundo asentamiento poblacional, en el período de la Venezuela Petrolera, paralelo a los gobiernos del Sr. Carlos Andrés Pérez y el Dr. Luís Herrera Campins; la estructura física de las viviendas comienzan a cambiar, pasan de material de láminas de zinc a concreto, incorporándose algunos servicios básicos como: electricidad, red de gas natural, recolección aseo urbano y agua distribuida por camiones cisternas, mejorando así la calidad de vida de los habitantes. En vista de estos acontecimientos comenzaron las migraciones (invasiones) a terrenos baldíos y se promueve la construcción de viviendas rurales en el sector Las Quince Letras.

Para 1992 - 2009, surge el tercer asentamiento poblacional, caracterizado por la Venezuela Contemporánea, en el gobierno del Comandante Hugo Rafael Chávez Frías. El Sector fue creciendo y de esta manera surgieron las comunidades: Mecocal, Simón Bolívar y Corazón de Mara. En vista del crecimiento poblacional, surgieron tres centros educativos, estos son: Educación Inicial: Leonor de Fernández (extensión de la U.E. Leonor de Fernández). Escuela Especial U.E Guillermina Portillo y Aldea Universitaria La Nueva Lucha, ésta en el 2007, es construida en terreno donados por la familia Celis Añez. Asimismo, surgen servicios gubernamentales: Punto de Control de la Guardia Nacional, Sub-estación Eléctrica, e Instituciones de la Sociedad Civil: Concejo Comunal. También, se construyen centros comerciales con cuatro y hasta doce locales aproximadamente, un centro nutricional, varias líneas de autos por puestos, una antena Movilnet y cuatro Iglesias entre cristianas evangélicas y católicas.

Actualmente, existen proyectos de expansión como: catorce locales comerciales, dos canchas deportivas, instalaciones en la U.E. Leonor de Fernández (tercera etapa), servicio Winka (agua potable por tuberías) y complejos habitacionales para docentes (Villa Mar). Cabe destacar que este sector, ha ido creciendo paulatinamente en población, dando origen al surgimiento de dos comunidades, Shipia Wayuú y Santa Ana. Actualmente, "La Nueva Lucha", tiene una población de 134 familias aproximadamente, para un total de 680 habitantes, entre niños, adolescentes y adultos. Cabe destacar que esta comunidad se ha convertido en centro de abastecimiento para sectores adyacentes, contribuyendo al desarrollo económico y social, aunque se sigue practicando la actividad agrícola y ganadera (Cartográfica 2).

Problemas y Alternativas del Sector: Entre los problema que posee la comunidad, se destaca la escasez de agua potable (21.9\%), insuficiencia de asfaltado (21.3\%), deterioro del alumbrado eléctrico (9.6\%), inseguridad (8.5\%) e incumplimiento del aseo urbano (8.0\%). De lo expuesto surgen alternativas de solución, entre las más significativas están: que los Consejos Comunales trabajen unidos (40.6\%) y solicitar ayuda al gobierno nacional, regional y municipal (22.5\%) (Tabla 12). 


\subsubsection{Guía de Información del Subsistema Construido:}

A). Uso del Espacio: En relación al uso del suelo en La Nueva Lucha, se encuentra ocupado por diferentes establecimientos comerciales como distribuidoras de alimentos al mayor y detal, supermercados, farmacias, ferreterías, panaderías, pizzerías, tostadas, restaurantes, centro de conexiones, quincallas, estéticas, fruterías entre otros. Además, se destacan los centros educativos que van desde preescolar a educación superior, iglesias, fábricas, centros recreativos, médicos asistenciales y los espacios residenciales, favoreciendo el desarrollo de la comunidad (Cartográfica 3).
B). Trama Urbana: Ésta se evidencia por medio de la representación cartográfica que muestra el fraccionamiento del espacio, el cual se observa desigualmente distribuido. El sector se divide en manzanas, ubicadas mayormente en el sur, diferenciadas con manchas de color fuerte. También, se observa un espacio medianamente poblado al Oeste, diferenciado con marrón menos oscuro, ocupado por terrenos de una a veinte hectáreas, subdivididos en parcelas con linderos, ciclón o concreto.

Del mismo modo, se tiene en el centro Oeste una población dispersa (marrón claro), caracterizada por poseer una quinta parte habitada, cuyo terreno cuenta con veinte

Tabla 12

Problemas comunitarios y alternativas de solución

\begin{tabular}{|c|c|c|c|c|c|c|c|}
\hline Problemas & V.A & $\begin{array}{l}\text { V.R } \\
(\%)\end{array}$ & Cat. & Alternativas & V.A & $\begin{array}{l}\text { V.R } \\
(\%)\end{array}$ & Cat. \\
\hline Escasez de agua & 41 & 21.9 & \multirow{5}{*}{$\begin{array}{c}\text { Rango } \\
\text { Fuerte } \\
\quad>\end{array}$} & Que los consejos comunales trabajen unidos & 35 & 40.6 & \multirow{2}{*}{$\begin{array}{c}\text { Rango } \\
\text { Fuerte } \\
>\end{array}$} \\
\hline Insuficiencia de asfaltado & 40 & 21.3 & & Pedir ayuda al gobierno y alcaldía de Mara & 22 & 25.5 & \\
\hline $\begin{array}{l}\text { Deterioro de alumbrado } \\
\text { eléctrico }\end{array}$ & 18 & 9.6 & & $\begin{array}{l}\text { Asesoramiento a los miembros del consejo } \\
\text { comunal para presentar proyectos y ejecuten los } \\
\text { existentes. }\end{array}$ & 12 & 13.9 & \multirow{4}{*}{$\begin{array}{c}\text { Rango } \\
\text { Débil } \\
<\end{array}$} \\
\hline Inseguridad & 16 & 8.5 & & $\begin{array}{l}\text { Los cuerpos de seguridad hagan comisiones de } \\
\text { patrullaje para evitar la inseguridad }\end{array}$ & 9 & 10.4 & \\
\hline $\begin{array}{l}\text { Incumplimiento del aseo } \\
\text { urbano }\end{array}$ & 15 & 8.0 & & $\begin{array}{l}\text { El consejo comunal organice ornadas de toma de } \\
\text { conciencia para el buen uso de los servicios }\end{array}$ & 5 & 5.8 & \\
\hline $\begin{array}{l}\text { Imperfecciones en } \\
\text { mangueras de gas }\end{array}$ & 9 & 4.8 & \multirow{8}{*}{$\begin{array}{c}\text { Rango } \\
\text { Débil } \\
<\end{array}$} & $\begin{array}{l}\text { La alcaldía y consejo comunal tomen medidas en } \\
\text { el tratamiento del agua y otros problemas }\end{array}$ & 3 & 3.4 & \\
\hline Deficiencia de vivienda & 9 & 4.8 & & Total & 86 & $99.6 \%$ & \\
\hline $\begin{array}{l}\text { Ausencia de aceras y } \\
\text { brocales }\end{array}$ & 9 & 4.8 & & & & & \\
\hline Falta de red de cloacas & 8 & 4.2 & & & & & \\
\hline Descuido de Áreas verdes & 7 & 3.7 & & & & & \\
\hline Privación de acueducto & 7 & 3.7 & & & & & \\
\hline $\begin{array}{l}\text { Falta d abastecimiento en } \\
\text { comedor comunitario }\end{array}$ & 6 & 3.2 & & & & & \\
\hline $\begin{array}{l}\text { Debilidades en organismos } \\
\text { competentes }\end{array}$ & 1 & 0.1 & & & & & \\
\hline Total & 187 & $99.0 \%$ & & & & & \\
\hline
\end{tabular}

Aplicación del Método de los Conjuntos: $M=100 / N$. $M=100 / 13=7.6 ; 100 / 6=16.6$.

Nota: V.A: Valor Absoluto V.R: Valor Relativo (\%) Cat: Categoría. Mayor Que (>), Menor Que (<)

Fuente: Encuesta Socioeconómica. II Etapa de Educación Básica. Elaboración: Equipo de Investigación 2014. 
hectáreas, donde anteriormente se practicaba la cría avícola y cultivos (Cartográfica 3). Al Este se divisa la primera casa del sector, ella posee un valor patrimonial histórico por su antigüedad (más de 50 años construida), la misma se encuentra olvidada por los habitantes de la comunidad, su entrada se muestra cubierta de árboles, que le restan visibilidad, formando un ecosistema natural. Asimismo, en el área se encuentran los primeros fundadores del Sector, la familia Celis Añez, la cual construyó una nueva casa en la vía principal que lleva por nombre Casa Grande, según informantes claves.

C). Vías de Acceso (circulación): Por su ubicación geográfica, cuenta con rutas inter-urbanas que dan acceso a otros sectores (Cuatro Bocas y Santa Cruz de Mara) y municipios (Maracaibo, Guajira e insular Padilla), posee una ruta principal que parte desde este sector hacia San Rafael de El Moján, Río Limón, Simanaica, Paraguaipoa y Paraguachon, hasta conectar con la localidad de Maicao (República de Colombia). La red vial es a través de autobuses (Moján, Rosita, Guana, Los Filuos, entre otros), microbuses (Maracaibo - Maicao, Cuatro Bocas - Maracaibo, Moján - Maracaibo), camiones, camionetas, autos por puestos (Nueva Lucha - Maracaibo; Nueva Lucha - Cuatro Bocas; Nueva Lucha-Simamaica; Nueva Lucha - Paraguaipoa) y existe una red de ambulancias, taxis y moto taxis que ofrecen sus servicios a la localidad.

El acceso al sector se puede visualizar a través de la representación cartográfica con líneas de color anaranjado, simbolizando la mayor fluidez vehicular, ésta posee tres intersecciones principales formando una $Y$. La vía con dirección hacia el Norte, conduce a San Rafael de El Moján, la trazada al Este, Maracaibo y al Oeste conecta con los centros poblados de Campo Mara-Carrasquero; la tonalidad amarilla es medianamente circulada y la de amarillo claro es menos transitada, por ser vías internas (Cartográfica 3).

D). Servicios Básicos (Públicos): Posee dos redes de gasoducto doméstico distribuidas adecuadamente para su utilidad. Una planta eléctrica que abastece la comunidad y poblaciones circundantes, y un sistema de tuberías de acueducto de aguas blancas provenientes del embalse Tulé, quien distribuye el agua a los sectores poblados tres veces por semana. El sector, actualmente cuenta con un proyecto macro denominado Winka (agua) para favorecer a un gran porcentaje de comunidades pertenecientes al municipio Mara. Del mismo modo, disfrutan de una antena de comunicación inalámbrica (Movilnet) que facilita y brinda cobertura comunicacional a sus habitantes. También, cuentan con una emisora de radio que ofrece beneficio social, cultural, educativo y religioso, aportando información relevante a la comunidad (Cartograma 3).

E). Rasgos Culturales: La población presenta celebraciones religiosas, tales como: reuniones colectivas (conciertos) y células religiosas. Se observa en algunos espacios la veneración a San Benito. Durante los fines de semana las familias comparten y se recrean, realizando reuniones entre amigos, salidas a granjas, espacios abiertos $u$ otros de interés turístico. La cultura predominante es la etnia Wayuú, donde la mujer utiliza la manta como vestido que las distingue de la población alijuna. Dicha etnia, realiza artesanía: chinchorros, bolsos, alpargatas y sombreros. Del mismo modo, celebran tradiciones como: danza wayuú y velorio de huesos.

En relación a los modelos de comportamiento, la mayoría son impuestos, adoptando conductas imitadas por familiares, 
vecinos, medios de comunicación como son: moda (peinados, vestimentas), diálogo, música (vallenato y reggaetón), modelando estilos de vida que se oponen a la cultura autóctona. La comunidad presenta particularidades, como es el caso de la familia Celis Añez, que se caracteriza por ser altruista, puesto que ha donado terrenos a la comunidad, para la construcción de la aldea universitaria y llevar cabo el proyecto de extensión (infraestructura) de la tercera etapa de la U.E "Leonor de Fernández".

F). Rasgos Políticos: Existe un Consejo Comunal que trabaja en pro de las necesidades poblacionales, este logró implementar el plan de viviendas para las familias más necesitadas. El sector plantea debilidades al integrarse en las reuniones convocadas ya que de 680 habitantes, sólo 120 acuden a la convocatoria. Hoy existen proyectos de mejoramiento y avances comunitarios: vialidades internas, viviendas, canchas deportivas, acueductos, mantenimientos de electrificación, casa comunal, créditos para el desarrollo agropecuario, entre otros.

\subsubsection{Guía de Información del Subsistema Productivo:}

A). Actividades Económicas: Permiten la generación de riqueza dentro de una comunidad, mediante la extracción, transformación y distribución de los recursos naturales o bien de algún servicio. La comunidad presenta diversidad de servicios comerciales brindándoles a sus habitantes variedad de productos necesarios para el consumo diario, abasteciendo a comunidades adyacentes, en cuanto a víveres al mayor y detal. Los establecimientos comerciales constituyen el factor predominante en la comunidad, ya que posee establecimientos, tales como: farmacias, panaderías, ferreterías, depósitos, restaurantes, fruterías, abastos, empresas: Galpón Polar, fabricación de mermela- da de Guayaba, Centro Frutícola del Zulia y el Frigorífico Socialista de Mara (matadero de reses a mayor escala) (Cartograma 3).

B). Actividades no Económicas: Se pueden mencionar el servicio de salud, constituido por un consultorio médico general, odontológico, clínica nutricional infantil (Dr. Américo Negrette), centro de diagnóstico integral (CDI) y sus servicios de ambulancia. En cuanto a la educación, el sector posee cuatro instituciones públicas: U.E. Leonor de Fernández, Centro de Educación Inicial Leonor de Fernández. U.E. Guillermina Portillo y Aldea Universitaria La Nueva Lucha. Entre los centros recreativos, se destaca: una cancha deportiva, dos clubes, Socima y Girasol, estos permiten realizar eventos especiales: conciertos, cumpleaños, bodas, exposiciones escolares y talleres (Cartograma 3).

\subsection{Representaciones Cartográficas}

En esta sección se presentan tres cartogramas geohistóricos, como expresión gráfica que muestran el uso y la dinámica socio-educativa, cultural y comunitaria que caracteriza el área objeto de estudio, bajo condiciones históricas determinado en un momento dado. En su construcción se tomó en cuenta al colectivo que conforma los miembros de la U.E. Leonor de Fernández y el contexto comunitario del sector La Nueva Lucha, espacio geográfico vinculados al área de influencia de la población escolarizada (Cartograma 1, 2 y 3). 

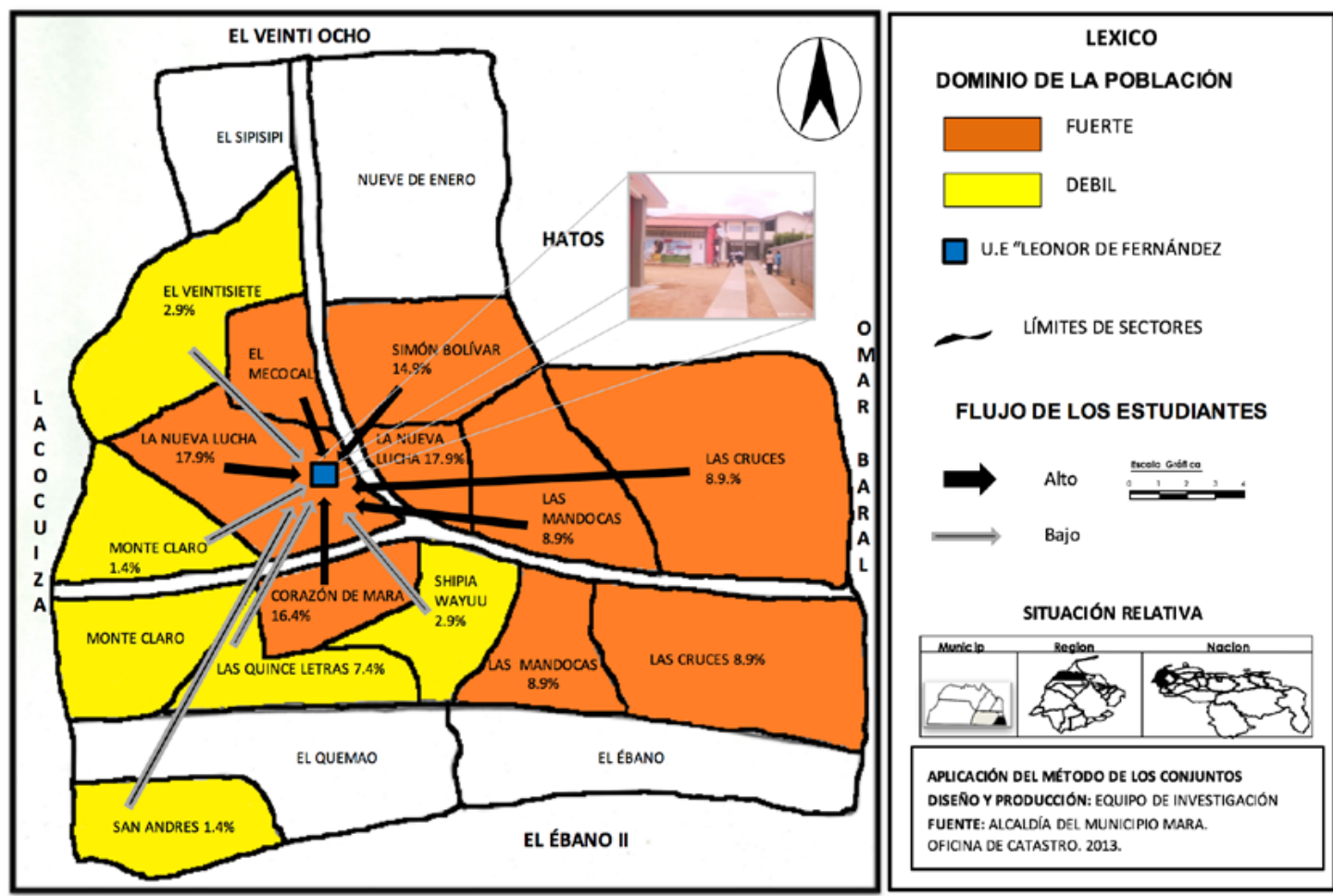

Cartograma 1: Área de influencia. Población escolarizada. Sectores: Parroquia Ricaurte Municipio Mara - Estado Zulia 2014 Fuente: Alcaldía del Municipio de Mara. Oficina de Catastro, 2013
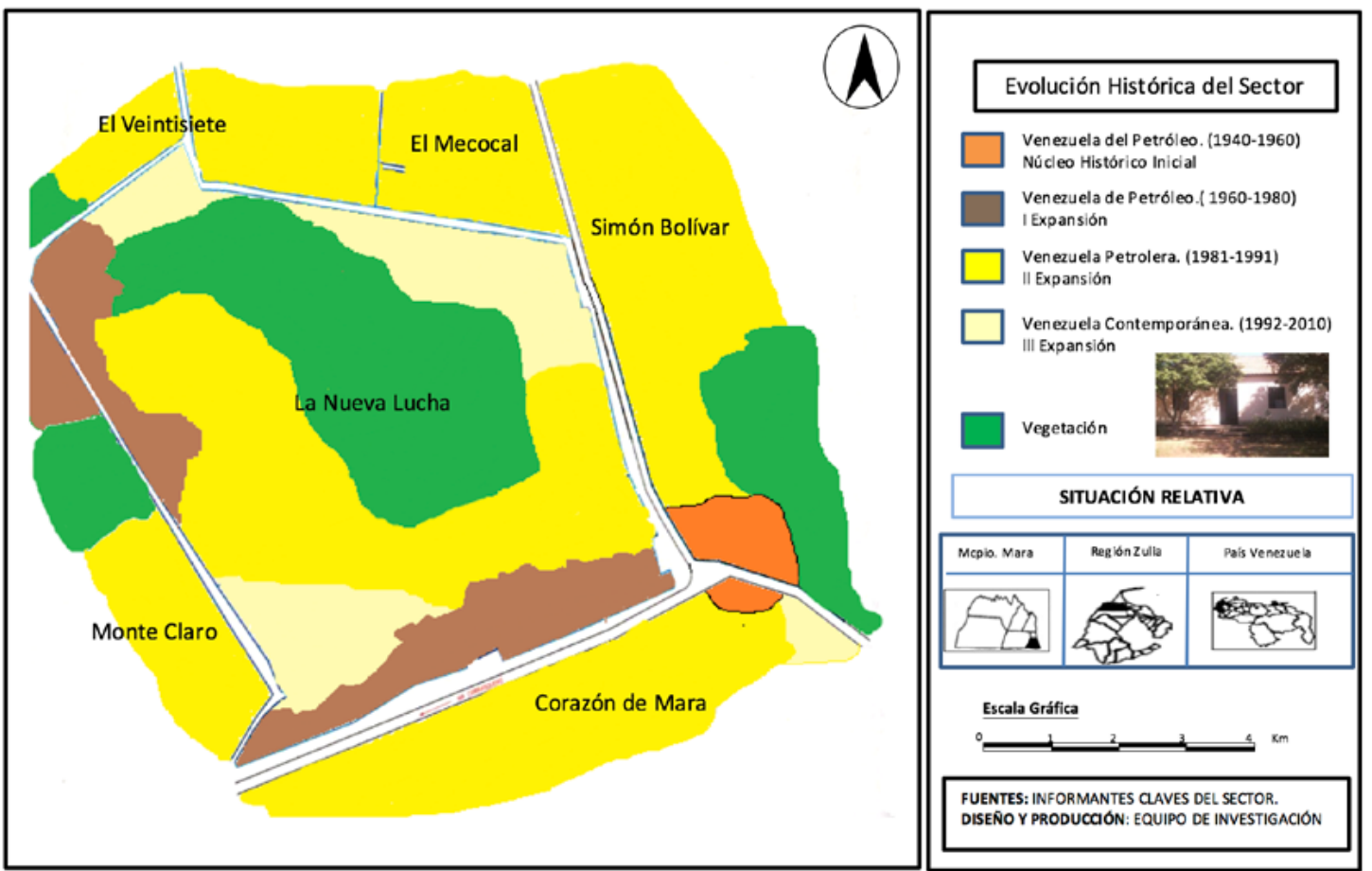

Cartograma 2: Evolución geohistórica. Sector La nueva Lucha, PArroquia Ricaurte Municipio Mara - EStado Zulia 2014 Fuente: Informantes claves del sector 


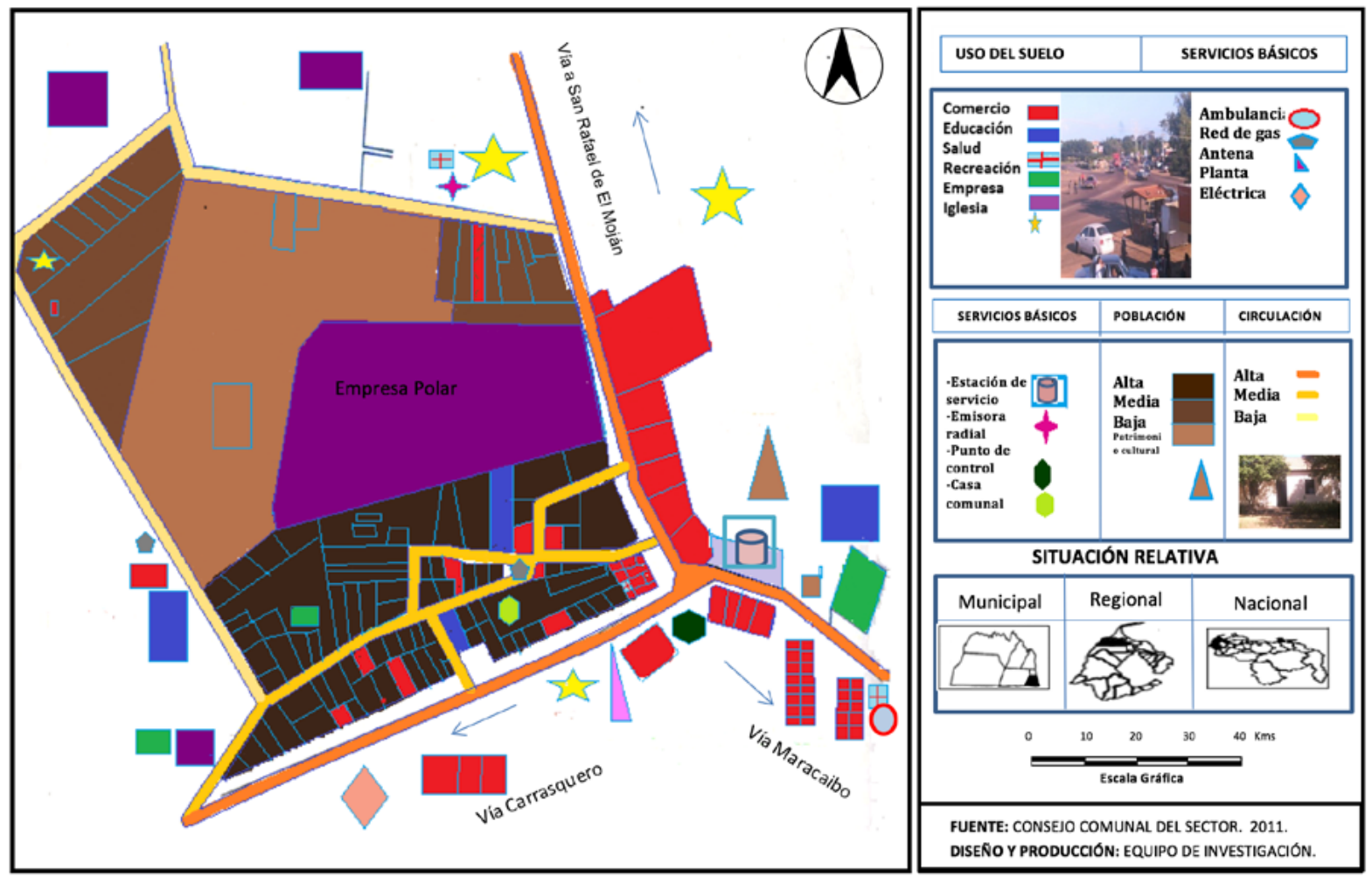

Cartograma 3: Subsistema construido sector La nueva Lucha. Parroquia Ricaurte. Municipio Mara - Estado Zulia, 2014.

Fuente: Consejo comunal del sector, 2011.

\section{Consideraciones finales}

- El diagnóstico de la comunidad como herramienta del enfoque geohistórico, conllevó a la describir de las condiciones socio-económicos, educativos, culturales y locales de la población que participó en esta investigación.

- En este estudio el método de los conjunto, permitió despejar la tendencia fuerte y/o débil presentes, para el análisis e interpretación de la dinámica espacial dominante en el área geográfica seleccionada.

- La cartografía como representación gráfica, facilitó la sistematización del proceso investigativo, puesto que a través de la réplica de la realidad geográfica, expresada en el documento se muestra la dinámica que caracteriza las contradicciones y leyes del sector La Nueva Lucha, municipio Mara.
- Se sugiere panificar y ejecutar contenidos de enseñanza apoyados en el diagnóstico de la comunidad, como herramienta del enfoque geohistórico, validad para abordar los aprendizaje de la geografía local y vincular los actores del proceso educativo (docente - estudiante escuela - comunidad), con su realidad inmediata, a fin de mejorar su calidad de vida, mediante la participación de ellos en sociedad. 


\section{Referencias bibliográficas}

Ancianis, E. (2007). Proyecto Educativo para la Enseñanza y Aprendizaje de la Geografía Local, desde la Geohistoria. Tesis de Maestría en Geografía, Mención Docencia. Universidad del Zulia. Maracaibo.

Arias, F. (2005). El Proyecto de la Investigación. Caracas Venezuela: Editorial Episteme.

Carvajal, G. (2001). Una Aproximación Teórica Metodológica al Estudio de la Geografía Local. Cuadernos digitales, №. 10. Costa Rica.

Cerda, H. (2005). Los Elementos de la Investigación. Bogotá: Editorial El Búho.

Ceballos, B. (2008). La Formación del Espacio Venezolano. Una propuesta para la Investigación y la Enseñanza de la Geografía Nacional. Tercera edición. (1 ed.1982 y $2^{\circ}$ ed. 1999). Caracas: Editorial FEDEUPEL.

Henríquez Fuentes, G. R. (2013). Investigación cualitativa en modelos de gestión logística y sus estrategias de desarrollo en la costa Caribe colombiana. Ad-Gnosis, 2(2), 65-85

Herrera, C., Lugo, R. y Pereira, A. (1991). "Diagnostico Geo-histórico y Socio - cultural del Sector 23 de enero. Barrio La Coromoto - El Recurso. Maracay". Geodidáctica. Vol. 4, Año IV, №5.

Ministerio del Poder Popular para la Educación. (2007). Currículo del Subsistema de Educación Primaria Bolivariana. Caracas - Venezuela: Edición CENAMEC.

Pérez, A. (2005). Guía Metodológica para Anteproyectos de Investigación. Caracas: Editorial Fedupel.

Romero, J., Ortega, J., Arango, J., Norgué, J., Albet, A., Méndez, R., Nel-Lo, O., Muñoz, F., Farinós, J.y Naredo, M. (2004). Geografía Humana. España: Editorial Ariel.

Santiago, J. (1997). Una aproximación a la Práctica del Docente que Enseña Geografía. Revista Geoenseñanza. Vol. 2.

Santiago, J. (2016). Otro discurso pedagógico y didáctico sobre la enseñanza de la geografía en el trabajo escolar cotidiano. Pensamiento Americano, 9(16), 171-188.

Sayago, A. y León, (2000). El Enfoque Geohistórico: Una Experiencia en la Praxis Educativa. Geoenseñanza. Vol. 6, 247- 276.
Sevillano, M. (2005). Didáctica en el siglo XXI. Ejes en el Aprendizaje y Enseñanza de Calidad. Madrid: Editorial Universidad Nacional de educación a Distancia.

Tovar, R. (1996) Enfoque Geohistórico, Academia Nacional de la Historia. Caracas: Editado por la Universidad de Carabobo. (1 ed. 1986). 